UC.15

Reporting Dole: July 1974

Issued: December 1974

\title{
Portal Monitor for Diversion Safeguards
}

by
W. H. Chambers
C. N. Fenry
F. F. Atwater
W. E. H.unz
P. E. Fehlau
T. E. Sompson
R. D. Hastings
T. H. Whittlesey

G. M. Worth 
Printeci in the United States of America. Available from National Technical Information Service

U.S. Depariment of Commerce

\$285 Port Royal Road

Springtield, VA 22151

Frice: Printed Copy $\$ 4.00$ Microfiche $\$ 2.25$

Tha Ier ot wix prepased os un acceunt of work sponsored by the United

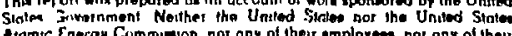

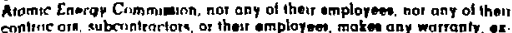

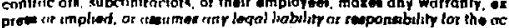

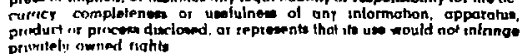




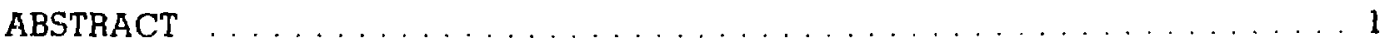

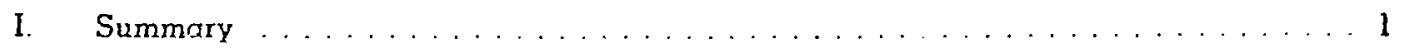

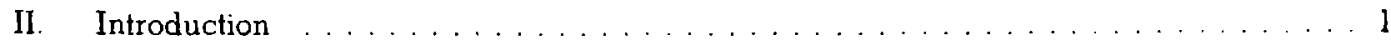

III. Detection Level and Confidence Intervals $\ldots \ldots \ldots \ldots \ldots \ldots \ldots \ldots \ldots \ldots$

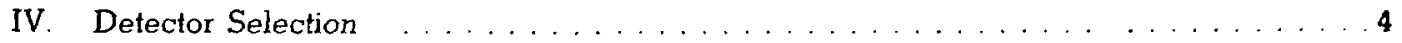

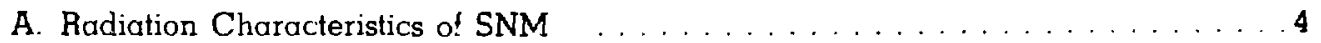

B. Figure of Merit for Detector Performance . . . . . . . . . . . . . . . . 7

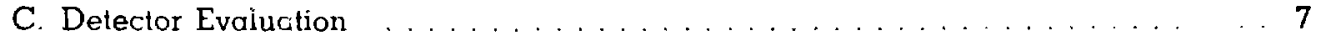

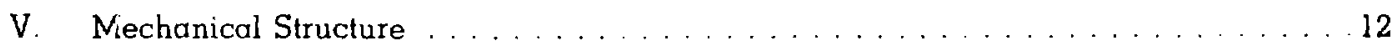

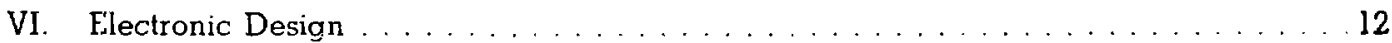

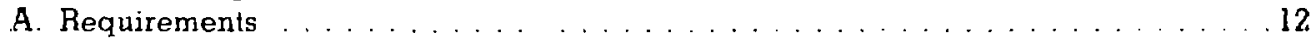

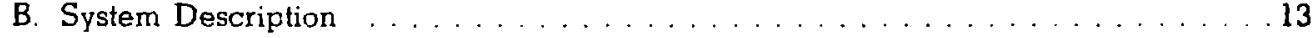

C. First Generation Warning Logic Module . . . . . . . . . . . . . . . . . . . . 15

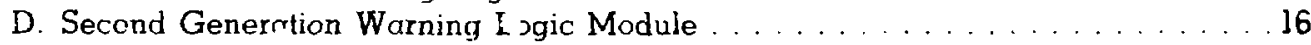

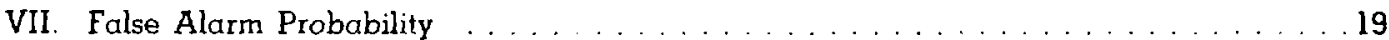

A. Calculational Method . . . . . . . . . . . . . . . . . . . . . 19

B. Results . . . . . . . . . . . . . . . . . . . . . . . . 19

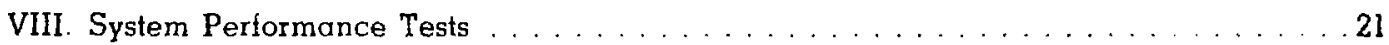

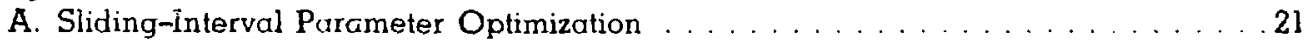

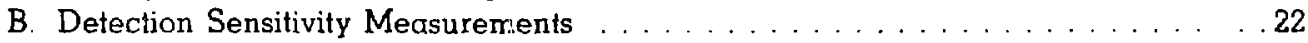

C. Envircnmental Testing . . . . . . . . . . . . . . . . . . . . . 25

D. Field Test Experience . . . . . . . . . . . . . . . . . . . . . . 27

1. Installation Requirements . . . . . . . . . . . . . . . . . 27

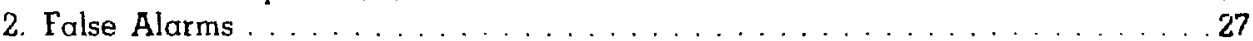

3. Film Results ... . . . . . . . . . . . . . . . . . . . 28

4. Alarm Rale Results . . . . . . . . . . . . . . . . . . . 28

IX. Portal Monitor Costs . . . . . . . . . . . . . . . . . . . . . .

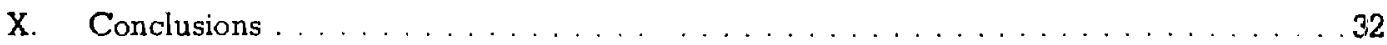

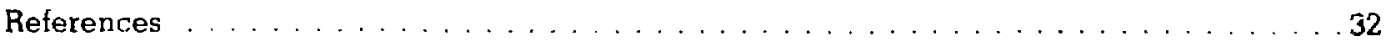

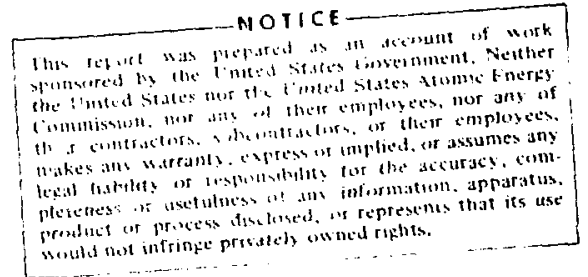




\title{
PORTAL MONITOF FOA DIVEHSION SAFEGUARDS
}

\author{
by
}

W. H. Chambors, H. Atwates, P. E. Fohlou,

D. D. Hastings. C. N. Henry, W. E. Kunz,

T. E. Sampson. T. H. Whitulosey, and G. M. Worth

\begin{abstract}
Two prototype porsonnel portal monitora why designed, constructed, and tested. These monitors cen be used at personnel oxits (rom apecial nucluar matertal (SNM) accans areas to duter the diversion of SNM. One protolype uses plastic selntillatons. the other conterins Nal(T) detectors. Bolb zinits heve a digital sliding-interval warning logic system. Dettection sensitivities of both unite for bure minimum surtaco-area samples are about $\mathrm{g}$ of $93 \%{ }^{233} \mathrm{U}$ and $0.1 \mathrm{~g}$ of weapons-grade pitutenium.
\end{abstract}

\section{SUMMARY}

The design, construction, and lesting of two prolotype personnel portal monitors have been com. pleted One unit uses four $51 \cdot \mathrm{mm}$-diam by $9.91 \cdot \mathrm{m}$. long plastic scintillator rods; the other protolyps contains four $127 \cdot \mathrm{mm} \cdot \mathrm{diam}$ by $25 \cdot \mathrm{mm}$-1héck Nal(T) detectors. Commercially available electronic com. ponents are used extensivoly, excep' for the alarm

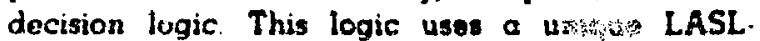
designed, digital, stiding-intervai tech logic module design and improvements is the original model are discussed in this raport.

A delecto: evaluation pregrum was curried out belore choosing the delectors described above. We summarize this evoluation and discuss in Sac. IV the detector selection crileria used.

Tests of the detection sensitivity used plutoniuses and both enriched and depleted uranium stimples in several geometrical conligurations. Delection sen. sitivities for both prolotypes were wecisly dentical, I to $4 \mathrm{~g}$ lor bate ${ }^{235} \mathrm{U}$ samples and opproximately $0.1 \mathrm{~g}$ for plutonium. The detection sensitivity's dependence on sample geometry cind shielding was investiguted and is reported in Ser VIII B

Field tests at several Los Alames Scientilic Labosatory (LASL) sites cre described in Sac. VIII D. These lests provided useful intormation on false alarm sates under realistic conditions. In port:culnt. they pointed out the umportence of the portel lecation on the false alurn rate

Considerable ellort was made to minimize the cos! of these prototypes As o sosuli, commercial versions of these designs may cost under $\$ 10000$

\section{INTRODUCTION}

In Novembet 1972, the U.S. AEC Division of Nuclear Motericl Security requested that LASL's Group A-2 seview the status of portal montcrs specilically designed for domestic dicersion saleguards. The request came, in part, because of the clese relationship of the purtal monitor problem to other on-going work on deteclors, data onalysis, and perimeler saleguards then under way in the group. Minimal lunding was made avaluble tor an odvanced. broadly applicable doorwry personnel monitor design and protolype model to be produced in abou! 6 months. This seport describes the initial design and tabrication of two protalypes as well as subsequent modifications and improvements aristng trom tests and evaluations done after the lirst 6 months

The general objective was to develop lurther the lechnology for delecting the concealed special 
nuclear material (SNM) on persons exiting from malerial access areas. A systemctic investigation of design parameters during the prototype development, we hoped, would provide suitable performance standards and would lead to a model having adequate sensitivity for plutonium and highly enriched uranium, low equipment and installation costs, minimum interference with normal personnel access, a low false alarm rate, and minimum training for maintenance and security personnel. Design information and improvements developed during the program were provided to interested instrument manufacturers. This was first dione in July 1973 through documentation and a demonstration conference. Further information regarding the improvements described in this report was distributed to the same manufacturers in April 1974. Based on results from the two prototy pes constructed, minimum performance standards for portal monitors at licenseexenupt AEC contracior facilities were proposed in Decomber 1973. Although these standards have not been universally accepted, they will be used by Group A.2 lor evalucting commercial instruments. AEC criteria currently are being proposed by amendments to AECM 2405, applicable to licenseexempt facilities, and to 10 SFR Part 73, covering licensees. A preliminary report of this work was presented at the November 1973 ANS meeting. 'This preliminary report, essentially unaltered from the ANS presentation, has also been published in the August 1974 issue of Niuclear Technology.

\section{DETECTION IEVELS AND CONFIDENCE INTERVAR.LS}

The slatistins of detection will be discussed briefly to defune some of the lerms that appear throughout this report.

The detector counts observed during a fixed counting interval are statistically distributed and follow a Poisson diatribution whose single parameter is the mean value $\mathrm{m}$. The standard deviation $\sigma$ of a Poisson distribution is $\sqrt{\mathrm{m}}$. The Poisson distribution is valid only for integer values of the variable $x$. The probability of abserving $x$ counts when the mean value is $m$ is given by

$$
P_{x}=\frac{m^{x} e^{-1}}{x !} .
$$

For values of $m$ of about 30 or greater, the Poisson distribution can be well approximated by the normal or Gcrulssian distribution with $\sigma=\sqrt{\mathrm{m}}$. For the nor- mal distribution the probability of observing a value lyir.g in $\mathrm{dx}$ ahout $\mathrm{x}$ is

$$
d P_{x}=\frac{1}{\sigma \sqrt{2 \pi}} e^{-\left[\frac{(x-m)^{2}}{2 \sigma^{2}}\right]} d x .
$$

The remainder of this discussion will be concerned with only the normal distribution, because it applies in almost all cases of interest. The probability of observing a value of $x$ that exceeds the mean value $m$ by some arbitrary amount is given by

$$
p(x>k)=\frac{1}{\sigma \sqrt{2 \pi}} \int_{k}^{\infty} e^{-\left[\frac{(x-m)^{2}}{2 \sigma^{3}}\right]} d x .
$$

Customarily $\mathbf{k}$ is given in multiples of the standard deviation $\sigma$. The probability of observing a variation above the mean of $\geq 2$ std dev is indicated by the cross-hatched area in Fig. 1. Probabilities of an observation $\mathrm{x}$ exceeding the mean value $\mathrm{m}$ by $\mathrm{k} \sigma$ or greater are given in Table I.

In the absence of an external radioactive source, the natural rudiation background will produce detector counts in a given time interval whose observed value $B$ is normally distributed about a mean value $\bar{B}$. This case is shown in Fig. I and Eq. 2 , where B corresponds to $x$ and $\bar{B}$ corresponds to $m$. The standard deviation of this distribution is $\sigma=\sqrt{\mathrm{B}}$.

Now assums the presence of a radioactive source that gives a net observed count $S$, which is also normally distributed about its mean value $\overline{\mathbf{S}}$.

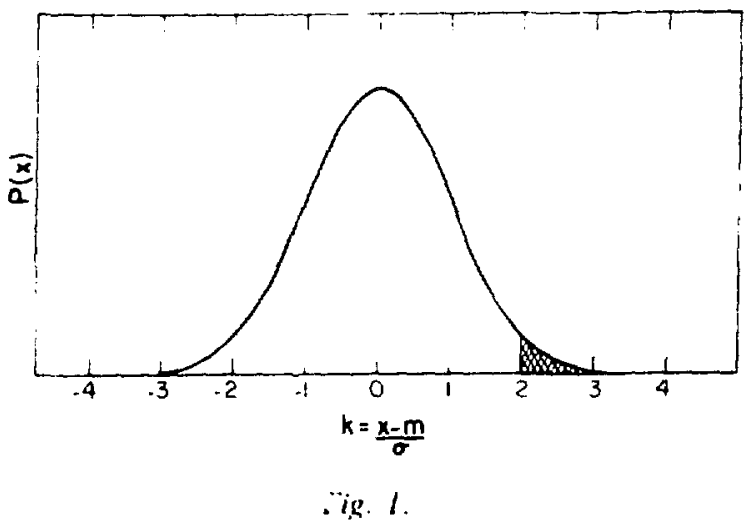

Divrihurion of the probability of oblaining a coume

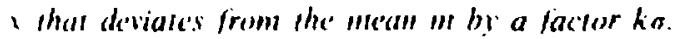
Hached area correyponds to prohability of obserring a deviation of In ar gresuler. 
TABLE I

\section{PROBABILITY OF DEVIATIONS}

$\begin{array}{cll}\mathbf{k}=\frac{\boldsymbol{x}-\mathbf{m}}{\sigma} & & \text { Probability } \\ & & \\ 0.0 & & 0.5000 \\ 0.5 & & 0.3085 \\ 1.0 & & 0.1587 \\ 1.28 & & 0.100 \\ 1.64 & & 0.0505 \\ 2.0 & & 0.0227 \\ 3.0 & & 0.00135 \\ 4.0 & & 0.0000317 \\ 5.0 & & 2.86 \times 10^{-7}\end{array}$

The observed total detector counts $\mathrm{S}+\mathrm{B}$ are normally distributed about a new mean $\overline{\mathbf{S}}+\overline{\mathrm{B}}$. Given the observed count $S+B$, we must determire if this represents $a$ statistically significant difference from the mean background $\bar{B}$ to conclude that a radioactive source is present. This is represented graphically in Fig. 2. If the observed count exceeds $a$ chosen detection level L, we have detected a source; and if the count is less than $L$, a source is not present. This statement can be made only if qualified with the proper probabilities, because two types of errors can occur. Following Altshule: and Pasternack, ${ }^{2}$ we call these Type-I and Type-II errors. A Type-I error occurs when no source $S$ is present, but the background fluctrations exceed the level L. This probubility is represented by the shaded area $\alpha$ in Fig. 2 and corresponds to the probability of falsely concluding that a source is present when it is not. We refer to this Type-l error as a statistical false alarm. A. Type-II error occurs when a signal is present but the observ-

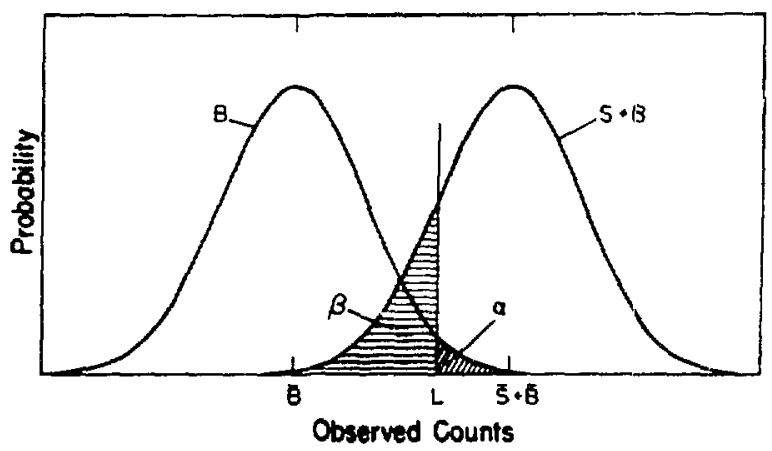

Fig. 2.

Probability distributions showing Type-I /hatched area $\alpha$ ) or Tipe-Il (hatched area $\beta$ ) errors for. mean background $\bar{B}$. alarm level $L$, and mean net signal $\bar{S}$. ed count $\mathrm{S}+\mathrm{B}$ is below the detection level $\mathrm{L}$, cnd it is falsely concluded that no source is present. This probability is zepresented by the batched orea $\beta$ in rig. 2. The area under the $S+B$ curve above the detection level represents the probability $l-\beta$. This is later referred to as detection probability or detec. tion confidence level.

To express the differences $L-\bar{B}$ and $(\bar{S}+\overline{3})-I$ in the units of $\sigma=\sqrt{\mathrm{S}}$ is common practice. Then tables of the normal probability distribution can be used to evaluate the false alarm probability $\alpha$ and the detection confidence $1-\beta$ for any selected value of the detection level $L$ and mean signal $\bar{S}$. Implicit in this discussion is the assumption that the standard deviation of the signal plus background distribution $\mathrm{S}+\mathrm{B}$ is equal to that of the background distribution B. This assumption is valid for reasonably large values of $\bar{B}$, detection levels $L$ that are close to $\bar{B}$, and contidence levels $1-\beta$ that do not greatiy exceed 0.95 .

Excmples of the use of these concepts follow. The numerical values closely approximate those pertinent to the portal monitors described in this report. Given a mean background count rate of 1200 crs and a counting interval of $0.6 \mathrm{~s}$ then $\bar{B}=1200 \times$ $0.6=720$ counts, and $a=\sqrt{B}=26.8$ counts. Assume what we call a $4 \sigma$ detection criteria. that is,

$$
\frac{L-\bar{B}}{\sqrt{B}}=4 \text {, }
$$

then $\mathrm{L}-\overline{\mathrm{B}}=4 \times 26.8=107.2$, and $\mathrm{L}=827.2$ counts. Thus, anytime a count accumulation greater than 827 is observed in a 0.6 -s count interval, we assume that a radioactive source has been detected. The probability that this is a false alarm from statistical fluctuations in the background is given by the area

$$
\alpha=p\left(\frac{x-\bar{B}}{\sigma}>4\right) .
$$

From Table 1 this fulse alarm probability is $3.17 \times 10^{-5}$ Because this probability is low, we very likely have detected a source with an observed count of 827 counts $/ 0.6 \mathrm{~s}$. However, we can make numerous assumptions regarding the source strength and its detection probability for the $4 \pi$ detection level of 827 counts. Two possibilities are shown in Fig. 3 . It the mean value of the signal results in a count of 107.2 counts $/ 0.6 \mathrm{~s}$ giving $\overline{\mathrm{S}}+\overline{\mathrm{B}}=107.2+720=827.2$ counts, then a number of trials would give the distribution shown as $\mathbf{S}_{50}+\mathrm{B}$. The subscript defines the 
detection confidence, which is the probability $1-\beta$ for a source count whose distribution has mean value of $\mathrm{S}_{50}+\mathrm{B}=\mathrm{L}$. This source would be detected with a detection contidence or probability of I - ${ }_{550}=50 \%$. A atronger source with a total mean count value $\overline{\mathbf{S}}_{95}+\overline{\mathrm{B}}$ will give a detection confidence or probability of $1-\not \mathrm{gs}=95 \%$ if its mean source strength is az additional 1.64\% greater than the 107.2 count source, that is, $\bar{S}_{95}-\bar{S}_{50}=1.64 \sqrt{g}_{\mathrm{B}}=44$ counts. The 1.64 factor arises from the difforence in $k$ between the $50 \%$ and $95 \%$ probabilitio given in Table I. Thus a source with a mean value of $\overline{\mathrm{S}}_{95}=107.2+44=151.2$ counts $/ 0.6 \mathrm{~s}$ would be defected with $95 \%$ confidence. This compares to the mean source strength of $S_{50}=107.2$ countw, which would be detected with $50 \%$ confidence.

In practice the detection level $L$ is generally determined by choosing a tolerable falee alarm probability (ir of Fig. 2). The epecitied censitivity then depends upon the detection contidence desired [ ] - - j), as il. lustrated for two cares in Fig. 3. We have chosen to specify sensitivity at the $50 \%$ detection confidence level. The additional wource strength needed for $95 \%$ detection confidence can be obtained trom the $\mathbf{5 0 \%}$ confidence value by multiplying it by the satio

$$
\frac{L(\sigma)+1.64 \sigma}{L(\sigma)}
$$

where $L(\sigma)$ is the detection level in unitu of $a=\sqrt{\bar{B}}$. For excmple, for a $4 \sigma$ detection level

$$
\frac{4+1.64}{4}=1.41
$$

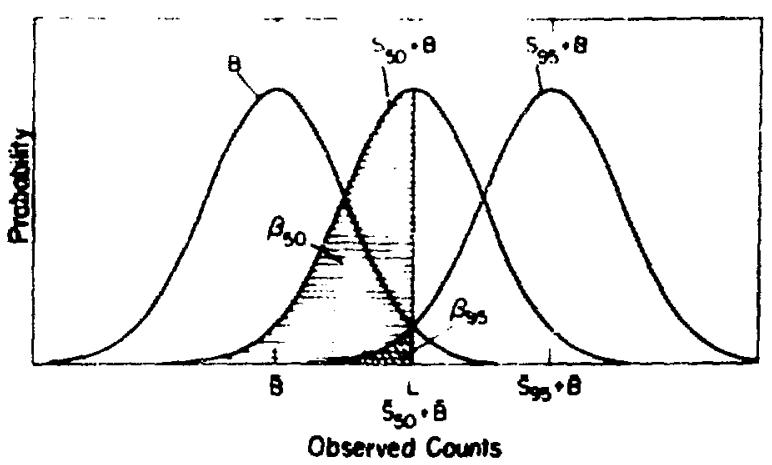

Fig. 3.

Probability distribustions illustrating difference between detection of mean signal $\mathcal{S}_{s t}$ with $50 \%$ confidence and delection of mean signal $\vec{S}_{95}$ with 95\% confidence with mean background $\bar{B}$ and alarm level $L$.
Thus a source 1.41 times greater in strength is needod for a $95 \%$ detection confidence than is required for $50 \%$ detection contidence. As noted later, this factor does not alway translate directly to source mass, because source strength is not always directly proportional to sicss for SNM.

\section{DETECTION SELECTION}

\section{A. Radiation Characteriatice of SNM}

The isotopes to be considered here are ${ }^{235} \mathrm{U}$, $239 \mathrm{Pu}$, and ${ }^{233} U$. The importance of the tiret two is obvious because of their potential use in nuclear weapons. Uranium. 238 is always found with $235 \mathrm{U}$ and therelore merits consideration. We will not discuses ${ }^{233} \mathrm{U}$. It is not yet as common as the cther three isotopes, and because of the high gamma cetivity of ${ }^{233} U$ and the ${ }^{232} \mathrm{U}$ daughters that are alwaye present, it does not present a difficult detection problem.

Uranium-235. The principal photon emieciuns from ${ }^{235} \mathrm{U}$ are at $186 \mathrm{keV}$, and the over present Aluorescent $x$ rays in the $100-k e V$ region. The $x$ raye can be geometry-dependent but are alwaye prewent in significant quantitios in gram-sized ramples of all SNM. No important higher onergy gamma emiscions from ${ }^{235} U$ occur. Bare samples do not precont a difficult detection problem. However, becaues of it low-energy smissions, ${ }^{225} \mathrm{U}$ can canily be thiolded, thereby making pactive detection by gamma-ray counting imposnible. Thin strong attenuation is s bown in Fig. 4 for tmo commion shiolding materials.

Plutonium-239. In addition to the $K x-r c 9$ complex around $100 \mathrm{keV}$. ${ }^{239} \mathrm{pu}$ emite trong lines at 129 $\mathrm{keV}, 208 \mathrm{keV}$ (from ${ }^{237} \mathrm{U}$, a ${ }^{24} \mathrm{Pu}$ daughter), a complex of gammas around 400 tro , and weaker gammcis in the 600-10 800-keV region. These are all overwhelmed by the 60 -keV gamma ray from ${ }^{211} \mathrm{Am}$ (a ${ }^{21} \mathrm{Pu}$ daughter that builds up with age). The ${ }^{241} \mathrm{Am}$ gamma and the trong $\mathrm{K} x$-raye are eavily absorbed. Howeyer, the large number of gammas above $200 \mathrm{keV}$ are more penetratiug and make detection of ${ }^{239} \mathrm{Pu}$ fairly easy even with modest shielding. The ${ }^{210} \mathrm{Pu}$ content of plutonium alss provides a neutron source of about $900 \mathrm{n} / \mathrm{s} \cdot \mathrm{g}{ }^{240} \mathrm{Pu}$. With the proper detector these neutrons could be used to detect large amount of beavily gammashielded plutonium. We have not pursued this detection mode for the personnel fortal, because suck a large amount of material and shielding cannot be concealed easily on a person. 


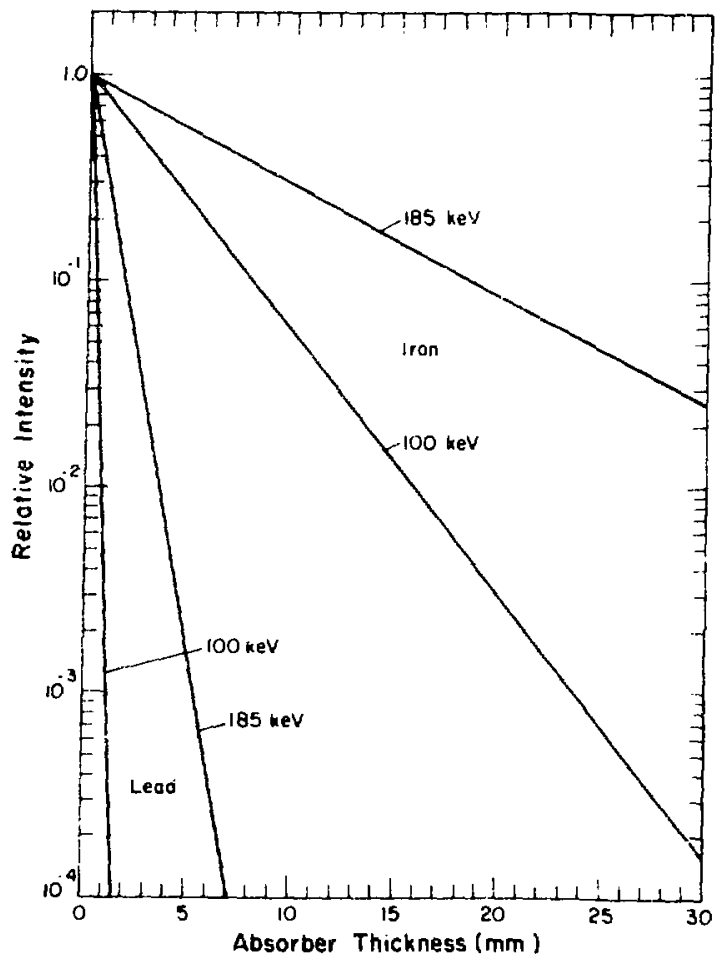

Fig.4.

Photon attenuation (narrow beam) for major emiswions of ${ }^{235} U$ for two common absoriters.

Uranium-238. The major emissions from ${ }^{238} \mathrm{U}$ come from its ${ }^{234 m} \mathrm{~Pa}$ daughter, which grows in with the 24.1-d half-iife of the intervening ${ }^{334} \mathrm{Th}$. These emissions include $a$ bremsstrahlung spectrum prominent below $500 \mathrm{keV}$ and low-intensity but penetrating gammas in the 700 - to $1000-\mathrm{keV}$ range. Very low. intensity, high-energy gammas up to $2000 \mathrm{keV}$ are generally not of practical use in portal monitoring applications. Of course, the uranium $\mathrm{K} x$-rays are also present.

Table II displays the gamma activity in various energy ranges for these isotopes. ${ }^{3.5}$ The age dependence of the ${ }^{238_{T}}$ daughter gamma activity could present a problem in areas where chemical separations are performed, for example, fuel reprocessing plants and enrichment facilities. Here "frosh" ${ }^{238} \mathrm{U}$ mary be found with oven less gamma activity than the weak listing in Table II.

Figure 5 shows pulse height spectra from these three isotopes in the 0- to $250-\mathrm{keV}$ range taken with a 127 -mm-diam by 25 -mm-thick NaI detector. These spectra are shown for illustrative purposes ouly, and the intensities should not be compared directly because different counting times, samples sizes, and source-detector distances were used. The spectial shopes, however, are representative of the particular sources and detector used. The fectures of these spectra ure not extremely geomery dependent, because all of these samples were intinitely thick for emissions in this energy range. Comparing Figs. 5
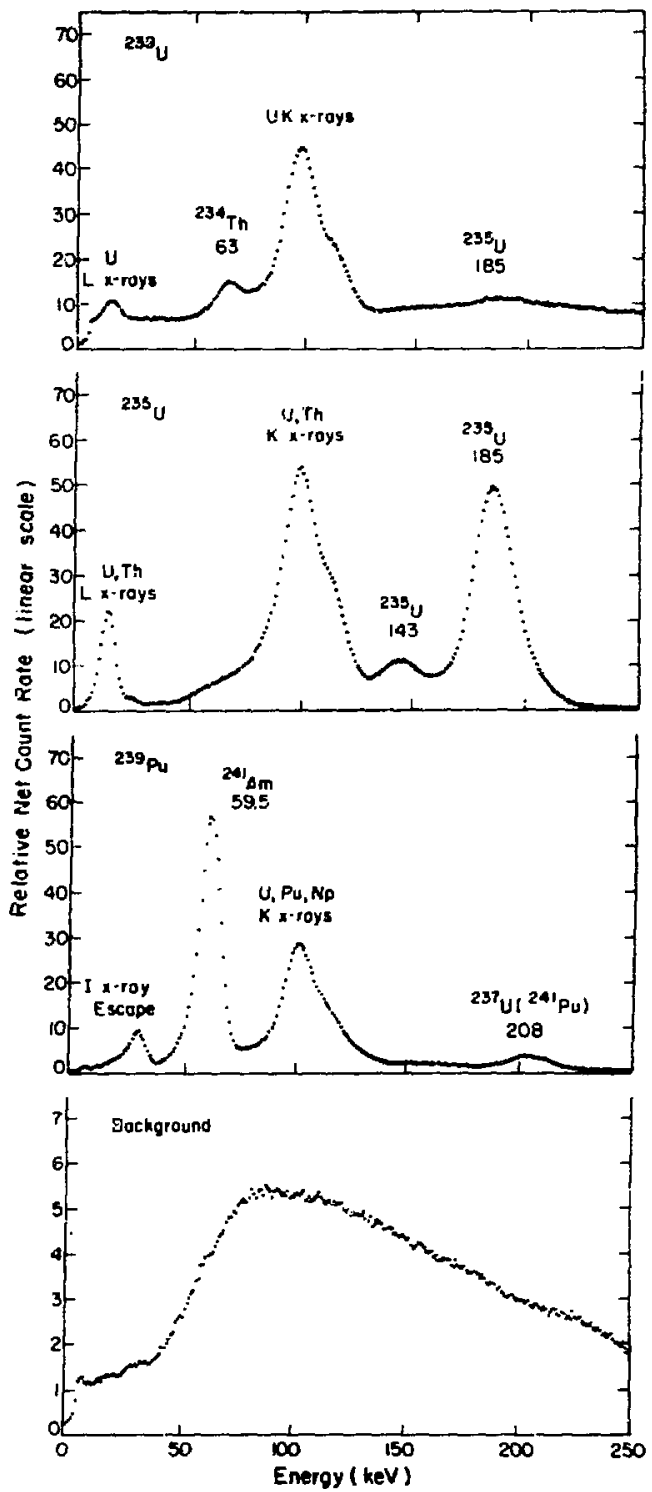

Fig. 5.

Typical pulse height spectra from SNM in 0.10 $250-\mathrm{keV}$ energy range. Detector is $127-\mathrm{mm}$-diam by 25-mm-1hick $\mathrm{NaI}(\mathrm{T} /$ ) with $0.25-\mathrm{mm}$ beryllium entrance window: Samples are right circular cylinders with height equal to diameter.

${ }^{23.9} U$ - 1002.6-g, 40.6-mm-diam, bare

${ }^{235} \mathrm{U}-98.59 \mathrm{~g} .18 .9-\mathrm{mm}-\mathrm{diam}$, bare

${ }^{239} \mathrm{Pu}$ - 0.918-g. 4.31-mm-diam. canned in $0.25-\mathrm{mm}$ stainless sleel. 


\section{TABLE II}

\section{GAMMA-RAY ACTIVITY OF SNM IN SELECTED ENERGY REGIONS}

\begin{tabular}{|c|c|c|c|c|}
\hline \multirow[b]{2}{*}{ Isotope } & \multirow[b]{2}{*}{$\begin{array}{c}\text { Decay Rate } \\
\text { (dps/g) }\end{array}$} & \multicolumn{2}{|c|}{ Gamma Activity } & \multirow[b]{2}{*}{ Comments } \\
\hline & & $\begin{array}{c}\text { Energy Range } \\
(k e V)\end{array}$ & $(\gamma / s-g)$ & \\
\hline${ }^{235} \mathrm{U}$ & $7.997 \times 10^{4}$ & $75 \cdot 210$ & $6.18 \times 10^{4}$ & $\begin{array}{l}\text { Does not include } \\
\text { geometry-dependent uranium } \\
\mathrm{K} \times \text { rays ir } 100-\mathrm{keV} \\
\text { region, which approximately } \\
\text { double the listed } \\
\text { intensity if included. }\end{array}$ \\
\hline${ }^{239} \mathrm{Pu}$ & $2.268 \times 10^{9}$ & $\begin{array}{r}80-770 \\
197-451\end{array}$ & $\begin{array}{l}3.33 \times 10^{5} \\
1.34 \times 10^{5}\end{array}$ & $\begin{array}{l}\text { Does not include } \\
\text { geometry-dependent plutonium } \\
\mathrm{K} \times \text { rays in } 100-\mathrm{keV} \\
\text { and age-dependent } \\
241 \mathrm{Am} \text { from }{ }^{241 \mathrm{Pu}} \\
\text { decay, which dominate } \\
\text { the spectrum and overwhelm } \\
\text { the jisted intensities. }\end{array}$ \\
\hline${ }^{238} \mathrm{U}$ & $1.244 \times 10^{4}$ & $\begin{array}{r}80-1001 \\
700-1001\end{array}$ & $\begin{array}{l}129 \\
121\end{array}$ & $\begin{array}{l}\text { Strong bremsstrahlung below } \\
500 \mathrm{keV} \text { from } \beta^{\circ} \text { of } \\
234 \mathrm{Th} \text { and geometry- } \\
\text { dependent uranium } \mathrm{K} \\
\times \text { rays in } 100-\mathrm{keV} \\
\text { region not included. }\end{array}$ \\
\hline
\end{tabular}

and 6 gives an idea of the relative magnitude of the low-and high-energy emissions from ${ }^{238} \mathrm{U}$ and ${ }^{239} \mathrm{Pu}$. Some of the low-energy continuum is, of course, scattered radiation from Compton events in the source and detector. The low-energy emissions dominate the spectra, although there are significant contributions from higher energy gammas ( $>200$. $\mathrm{keV}$ ) in the ${ }^{238} \mathrm{U}$ and ${ }^{239} \mathrm{Pu}$ spectra. Uranium-235 is not shown in Fig. 6 because it has no significant emissions above $205 \mathrm{keV}$.

For ${ }^{238} \mathrm{U}$ and ${ }^{239} \mathrm{Pu}$ the intensity ratio of high- to low-energy gammas depends on sample size and configuration because of self-attenuation effects. Ninety-five percent of the infinite thickness emission can be obtained from a sample thot is 3-mfp thick for the radiation of interest. This parametor is tabulated in Table III for uranium and several photon energiss of interest and is essentially the same for plutonium. Referring to Table III and the Fig. 5 caption, we note that the $1 . \mathrm{kg}{ }^{230} \mathrm{U}$ sample used for the spectra of Figs. 5 and 6 is infinitely thick for its $1-\mathrm{MeV}$ emissions, whereas the $1-g^{23}$ Pir sample has somewhat less than infinite thickness for its $400 \mathrm{keV}$ emissions.

The strong self-absorption of the dominant lowenergy gamma rays emitted by SNM means that for bare samples of these materials the total source strength is almost entirely dependent on the pro. jected surface area, not the sample mass. This

\section{TABLE III}

\section{URANIUM SELF-ABSORPTION}

\begin{tabular}{cc}
$\begin{array}{l}\text { Photon } \\
\text { Energy } \\
\text { (keV) }\end{array}$ & $\begin{array}{c}\text { Uranium Thickness for } \\
\text { 95\% of Infinite Thickness } \\
\text { Emission Rate } \\
\text { (mm) }\end{array}$ \\
\hline 100 & 0.85 \\
185 & 1.07 \\
400 & 5.64 \\
1000 & 20.8
\end{tabular}




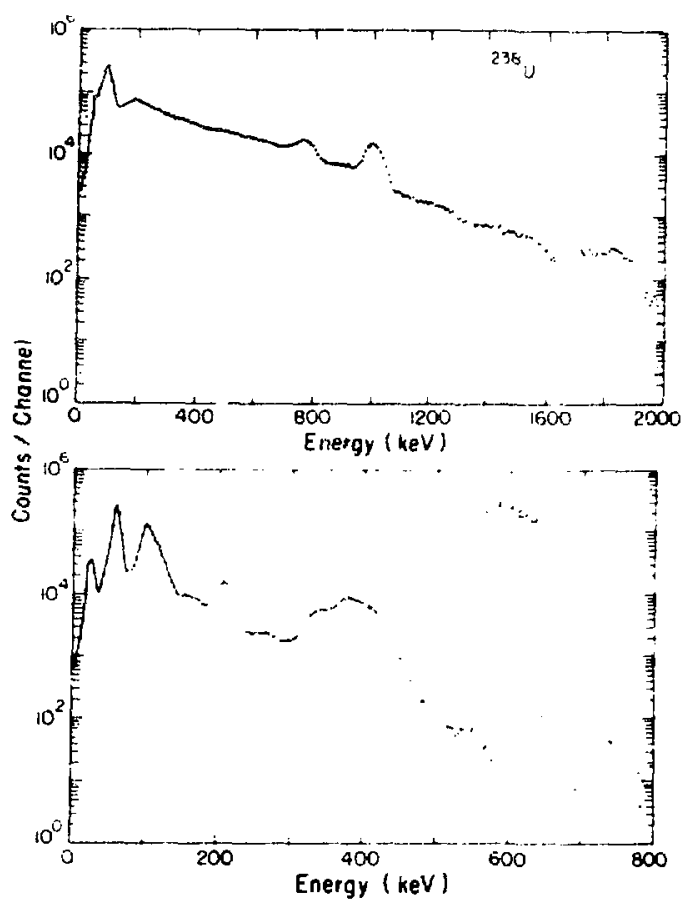

Fig. 6.

Typical pulse height spectra showing higher energy emissions from ${ }^{238} \mathrm{U}$ and ${ }^{239} \mathrm{Pu}$. Samples and detector same as Fig. 5.

becomes important when choosing samples to use in specifying doorway monitor performance.

\section{B. Figure of Merit for Detector Pexformance}

Many variables must be considered when choosing a detector for portal monitoring applications. These variables include intrinsic efficiency, detector geometry, detector size, spectral response characteristics, operational characteristics, and cosi. To find a Figure of Merit (FOM) to account for all these parameters is impossible; however, in an operating system the need to minimize that coun! time can be used to develop a meaningful FOM.

A personnel monitor that does nol impede traffic is desirable and is particularly important for laige facilities at shift-change times. To be able to pass through a monitor at normal walking speed without pause meass that the total time available for a count is $\leq 1 \mathrm{~s}$ for a 0.75 - $\mathrm{m}$-uride portai.

For given mean signal and background count rates, $\bar{s}$ and $\bar{b}$, the time for detection of the signal, given a detection criteria of net signal counts $=\mathbf{n} \cdot \mathrm{std}$ dev of the background counts, is:

$$
\begin{aligned}
\bar{s} t & =n \sqrt{\bar{b} t} \\
\bar{s}^{2} t & =n^{2} \bar{b} \\
t & =\frac{n^{2}}{\left(\bar{s}^{2} / \bar{b}\right)} .
\end{aligned}
$$

The minimum time for detection is inversely proportional to $\bar{s} 2 / \bar{b}$, where $\bar{s}$ and $\bar{b}$ are the mean signal and background count rates. This suggeste that $\bar{s}^{2} / b$ is a useful FOM for tefector evaluation, because the larger the value of $\bar{g}^{2} / b$, the shorter the detection time. We drop the mean value notation for convenience and for FOM purposes adopt the nota. tion $S^{2} / B$.

The $S^{2}$ / B FOM accounts for many of the detector variables previously menticned. The effects of intrinsic detector efficiency, deteclor size, delector spectral response, and to some extent, detector geometry are included. The parameters of operational characteristics and cost are not included but using $\mathrm{S}^{2} / \mathrm{B}$ per dollar can account for the cost. For a given detector and sample; $S^{2} / B$ itself can be optimized as c function of bias level or single-rhannel analyzer window settings. Comparisons between detector types are only meaningful if this optimization has been performed on all detectors.

\section{Detector Evaluation}

We mainly considered two types of detectors, $\mathrm{NaI}(\mathrm{T} /)$ and plastic scintillators. For this applicusion, we ruled out the use of liquid scintillators, beca se we have had problems with leakage from commercially-available liquid scintillators. In uddition, we felt that solid plastic scintillators could be used in various geometricel configurations more easily and more cheaply than the liquid types because plastic is easier to "package" than liquid.

Because we had a short time to evaluate plastic scintillator types, we drew heavily on the experience of the personnel at the Dow Chemical Corporation Rocky Flats Plant. ${ }^{6}$ We thoroughly evaluated cylindricai rods of NE-102 (Nuclear Enterprises, Ltd. San Carlos, California) in 25. and 51 -mm diameters similar to those Rocky Flats has used for the detection of plutonium. The requirement to Luild a "universal" portal mo:aitor led us to concentrate on evaluating the detectors for ${ }^{235} \mathrm{U}$, which presents a more difficult detection problem than plutonium. Almost any detector that does a good job for ${ }^{235} U$ will be more than adequate for plutonium because of the greater uctivity and higher gamma energies of ${ }^{239} \mathrm{Pu}$ relative to ${ }^{235} \mathrm{U}$. 
Plastic scintillators are difficult to use for low. energy photons. Their pulse height response to monoenergetic photons consists only of a Compton electron distribution, because their low- $Z$ constituenis have no significant photoelectric cross section above $100 \mathrm{keV}$. The need to bias out the high background and zoise at small pulse heights means that many counts are lost from the low-energy (100- to $200 \mathrm{keV}$ ) emissions from ${ }^{235} \mathrm{U}$. This efficiency foll-off at low energies is shown in the efficiency curves in Fig. 7. These data are taken from Roulston and Nagvi, ${ }^{7}$ who claim that measured efficiencies below $200 \mathrm{keV}$ are higher than these calculations, presumably due to multiple scattering. The difficulty in low-energy detection is illustrated by the fact that the maximum electron energy from $100-\mathrm{keV}$ gammas in plastic is cnly $28 \mathrm{keV}$ and that from $200-\mathrm{keV}$ garmmas is only 88 $\mathrm{keV}$ Pulse height spectra from samples of ${ }^{235} \mathrm{U},{ }^{23} \mathrm{U}$, and ${ }^{239} \mathrm{Pu}$, as well as from background are shown in Fig. 8 for a 51 -mm-diam by $914-\mathrm{mm}$-long rod of NE102 coupled to a 127 -mm-long light pipe and an RCA 4523 photomultiplier. These spectra are characterized by a smooth, featureless continuum rapidly rising at low pulse heights. They may be contrasted to the Nal spectra of Figs. 5 and 6. To help evaluate the proper thickness of a plastic scintillator for optimum detection, we also studied 127 -mm-diam cylincirical samples of NE-102 in thicknesses of 51 and $102 \mathrm{~mm}$. These were coupled to un RCA 4525 PMT

From provious experience with $\mathrm{NaI}(\mathrm{T}$ ) detectors, we concluded that $127-\mathrm{mm}$-diam by $25-\mathrm{mm}$-thick detectors provided a near-optimum compromise detector size for the wide range of energies ( $<100$ to $>1000 \mathrm{keV}$ ) emitted from SNM. Table IV shows the total intrinsic detection efficiency for several promi-

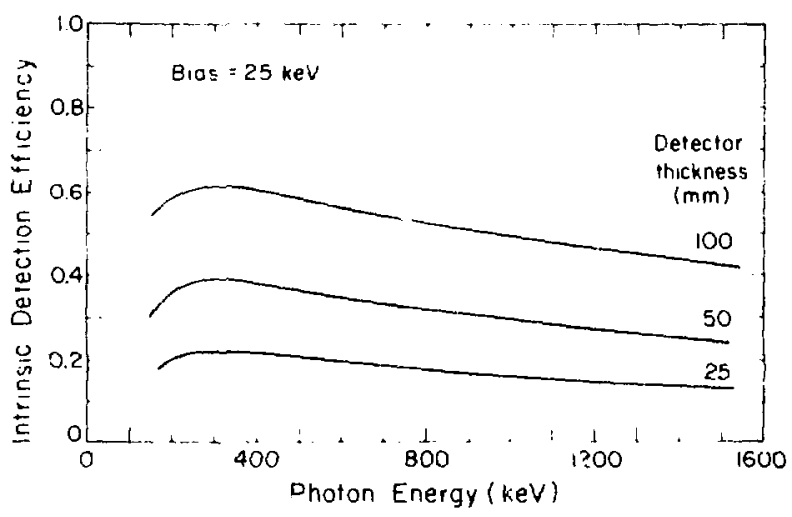

Fig. 7.

Imrinsic delection efficiency as a function of photon energy and detector thickness for a typical plastic sciniflator biased at $25 \mathrm{keV}$.
TABLE IV

\section{TO'TAL INTRINSIC DETECTION EFFICIENCIES FOR 25-IAM-THICK} NaI (T) DETECTORS

$\begin{array}{ccc}\begin{array}{c}\text { Enexgy } \\ \text { (keV) }\end{array} & \begin{array}{c}\text { Eticiency } \\ \text { (\%) }\end{array} & \text { Applicable Isotope } \\ 100 & 100 & \text { All SNM (K x rays) } \\ 185 & 97 & 235 \mathrm{U} \\ 400 & 65 & 239 \mathrm{Pu} \\ 1000 & 41 & 238 \mathrm{U}\end{array}$

nent emissions. These efficien cies may be compared with those for plastic scintillators shown in Fig. 7. The total detection efficiency (as opposed to photopeak efficiency) is the pertinent parameter to tabulate, because wide windows extending from below 100 $\mathrm{keV}$ to above the main gamma peaks generally maximize $S^{2} / B$ for a given source.

The total detection efficiency varies as $\left(1-e^{-\mu t}\right)$, where $\mu$ is the absorption coefficient and $t$ is the detector thickness. Therefore little is gained in using a detector more than about 1 -mfp (equal to $1 / \mu$ ) thick for the radiation of interest. This thickress gives an efficiency of $63 \%$, whereas doubling the thickness increases the efficiency only to $86.5 \%$ but greatly increases the cost, which can become an overriding factor in NaI(T) systems. Under this criteria a 25mm-thick detector should be ideal for plutonium, overly thick for ${ }^{235} \mathrm{U}$, and slightly thin for ${ }^{238} \mathrm{U}$. However, considering the lower energy bremsstrathlung emissions from ${ }^{238} \mathrm{U}$, a 25 -mm-thick detector is a good compromise for all energies of interest from SNM. This size provides a large detection area $\left(126.7-\mathrm{cm}^{2}\right)$ for a relatively low cost (approximately $\$ 625$ ). Its main disadvantages are that its response $d x$, ps rapidly off axis and that it has the same temperature problems that most $\mathrm{NaI}$ detectors have (thermal shock can fiacture the cryatal).

We looked in less detail ct a FIDLER-type ${ }^{8}$ detector [127-mm-diam by $1.6-\mathrm{mm}$-thick $\mathrm{NaI}$ (T/) with $0.25-\mathrm{mm}$ br Iyllium entrance windowi with the thought that it could be valuable for detecting lowenergy fluorescent $x$ rays asd scattered degraded energy photons from heavily shielded samples. Proportional counters and Geiger counters were also examined, mainly because of their low cost.

Two commercially available instruments were evaluated for use in this portal moritoring problem. Both the Eberline model PMP-4 Beta Gamma Portal Monitor and the Reuter-Stokes RSS-111 Environmental Raciation Monitor lacked adequate sensitivity, 
time response, or bath to be applicable. These in struments were not designed for this purpose, therefore this judgment in no way applies to tneir use in their intended apnlication.

The results of evali:ating several detecto: types with a bare ${ }^{235} \mathrm{U}$ sample are listed in Table V. Clearly the $127-\mathrm{mm}$ by $25.4-\mathrm{mm} \mathrm{NaI}(\mathrm{T})$ is superior on both an $S^{2} / B$ and $S^{2} / B$ per dollar basis. However, this does not tell the whole story, because the cost per unit is about iwice that of the plastic scintillators. The totcl system cost is an important parameter, which can conflict even with a "most detection per dollar" FOM. Because the 914-mm-long plastic rods are used vertically, the response of four such rods covering a 2.1 -m-high doorway is fairly uniform, more uniform than that with four $\mathrm{NaI}$ detectors that cost nearly twice as much.

Although this table does not show it, the FIDLER $\mathrm{NaI}$ was found to be slightly superior to the $127-\mathrm{mm}$ by $25-\mathrm{mm} \mathrm{NaI}$ only for the heavily shielded case (17.6-mm $\mathrm{Pb}$ ). However, with this shielding, the count rate is so low (see Fig. 4) that with count times of the order of $1 \mathrm{~s}$ neither system could detect an enriched ${ }^{235} U$ sample, so the comparison is academic.

The measured $S^{2} / B$ values in Table $V$ are optimum values for all detectors listed except for, perhaps, the 25-mm-diam by 914-mm-long NE-102 rod. This value may be nonoptimum, but even a factor of 4 increase does not make it competitive with the 51 -mm-diam rod whose cost is nearly the same.

The optimum windows for maximizing $\mathrm{S}^{2} / \mathrm{B}$ were determined with the aid of a computer program that lisied a cumulative sum of the net signal count rate and background count rate as a function of energy. Suhtracting the listings for any two energies gave the $\mathrm{S}$ and $\mathrm{B}$ for the window defined by those energies. The optimum windowe were then found by trial and error.

TABLE V

DETECTOR EVALUATION FOR ${ }^{235}$ U DETECTION

\begin{tabular}{|c|c|c|c|}
\hline Detection & Measured $S^{2} / B^{\alpha}$ & $\begin{array}{c}\text { Estimated } \\
\text { Cost }^{c} \\
(\$)\end{array}$ & $\frac{s^{2} / B}{\text { Dollax }}$ \\
\hline $\begin{array}{l}\mathrm{NaI}, 127 \mathrm{~mm} \text {-dicm } \\
\text { by } 25.4 \mathrm{~mm} \text {-thick }\end{array}$ & 35500 & 625 & 56.8 \\
\hline $\begin{array}{l}\text { Nal, 127-mm-diam } \\
\text { by l.6-mm-thick } \\
\text { (FIDLER) }\end{array}$ & 20100 & 1000 & 20.1 \\
\hline $\begin{array}{l}\text { NE-102 } \\
127-\mathrm{mm} \text {-diam } \\
\text { by } 102 \text {-mm-thick }\end{array}$ & 11600 & 285 & 40.7 \\
\hline $\begin{array}{l}\text { NE-10乞 } \\
127-\mathrm{mm} \text {-diam } \\
\text { by } 51-\mathrm{mm} \text {-thick }\end{array}$ & 9860 & 240 & 41.1 \\
\hline $\begin{array}{l}\text { NE-102 } \\
51-\mathrm{mm} \text {-diam } \\
\text { by } 914-\mathrm{mm} \text {-long }\end{array}$ & 8300 & 350 & 23.1 \\
\hline $\begin{array}{l}\text { NE-102 } \\
25-\text { mm-diam } \\
\text { by } 914 \text {-mm-long }\end{array}$ & 660 & 290 & 2.3 \\
\hline $\begin{array}{l}\text { Geiger Tube } \\
\left(129-\mathrm{cm}^{2}\right)\end{array}$ & $40^{b}$ & 60 & 0.7 \\
\hline
\end{tabular}

\footnotetext{
${ }^{a}$ Measured with unshielded ${ }^{235} \mathrm{U}$ disk source (51-mm-diam, $0.51-\mathrm{mm}$-thick, $22-\mathrm{g}$ ) $610 \mathrm{~mm}$ from detector.

bxtrapolated from measurement on $15.9-\mathrm{mm}$-diam by 203-mm active length GM tube.

${ }^{\circ}$ Cost includes scintillator PM tube and voltage divider.
} 
The 127-mm by 102-mm NE-102 detector is somewhat better than the $51-\mathrm{mm}$-diam rod, but suffers one of the same problems as the 127 . $\mathrm{mm}$ by 25 $\mathrm{mm} \mathrm{NaI(T/),} \mathrm{that} \mathrm{of} \mathrm{poor} \mathrm{off-axis} \mathrm{response.}$

The comparison of several detector types as a function of sample shielding is given in Tables VI and VII. In Table VI ( ${ }^{235} \mathrm{U}$ sample) note the very rapid decrease in $S^{2} / B$ with added shielding. Also, the optimum window changes from 70- to $220-\mathrm{keV}$ for a bare sample to 160 - to $220-\mathrm{keV}$ for a shielded sample. Both bare and shielded configurations cannot have optimum detection simultaneously with a singlechannel system. A similar effect is seen for $238 \mathrm{~J}$ in Table VII. Here the fall-off in $\mathrm{S}^{2}$ / B with shielding is less rapid than for ${ }^{235} \mathrm{U}$ because the gammas from ${ }^{238} \mathrm{U}$ daughters are higher energy and more difficult to shield. The lower level setting of the optimum window changes in a continuously increasing manner as the shielding is increased. These data show that for a two-channel system and $127-\mathrm{mm}$ by $25-\mathrm{mm} \mathrm{NaI}(\mathrm{T}$ ), nearly optimum detection windows for ${ }^{235} 5_{U}$ and ${ }^{238} U$ can be obtcined simultaneously with only one singlechannel analyzer (SCA) by setting the SCA window for ${ }^{235} \mathrm{U}$ detection (about 70 - to $220-\mathrm{keV}$ for a bare sample) and by using the lower level discriminator output to approxima:e an optimum window for ${ }^{238} \mathrm{U}$. In this case the ${ }^{238} \mathrm{U}$ window becomes 70 - to $\infty-\mathrm{keV}$ instead of the optimum 13. to i 130-keV, but this only reduces $\mathrm{S}^{2} / \mathrm{B}$ by $6 \%$.
For ${ }^{239} \mathrm{Pu}$ the optimum SCA windows ys shielding thickness for a $127-\mathrm{mm}$ by $25-\mathrm{mm} \mathrm{NaI}(\mathrm{T})$ are given in Table VIII. This table illustrates ngain how the optimum window changes with shielding. For plutonium a compromise window of 0 - to $440-\mathrm{keV}$ does not seriously degrade detection capability for any of the shielding configurations.

A clear-cut choice for a single detector for the portal monitor system did not exist. The advantages of the high intrinsic efficiency and resolved pulse height distribution of $\mathrm{NaI}$ are offset by its relatively high cost, sensitivity to thermal shock, and poor offaxis response for the $127-\mathrm{mm}$ by $25-\mathrm{mm}$ configuration. Plastic is less expensive; the rods have a smenoth (but not uniform) axial response; and they can be easily made in large cross-sectional areas to compensate for their lower intrinsic efficiency. Small bias level shifts can cause large background changes beccuse $c^{\prime}$ the steeply rising pulse height distribution at low energies (Fig. 8). This disadvantage can be largely offset, however, by using stable electronics and an automatic background updating logic system.

Considering the number of parameters involved, we decided to build both an $\mathrm{Nal}$ and a plastic system to sompare directly their operation. The NaI system used four 127 -mm-diam by 25 -mm-thick NaI(T/) detectors for a detector cost of about $\$ 2500$. Although a six-detector version would have greater eensitivity

\section{TABLE VI}

\section{DETECTOR EVALUATION WITH SHIELDED 235 U SAMPLE ${ }^{\alpha}$}

$\frac{\text { Detector }^{c}}{127-\mathrm{mm} \text { by } 25-\mathrm{mm} \mathrm{NaI}}$
127-mm by 1.6-mm NaI
(FIDLER)
127-mm by 102-mm
NE-102
127-mm by $51-\mathrm{mm}$
NE-102

\begin{tabular}{|c|c|c|}
\hline \multicolumn{3}{|c|}{$\mathbf{S}^{2} / \mathbf{B}$ for Given Sample Shielding ${ }^{b}$} \\
\hline Bare & $1.6 \mathrm{~mm} \mathrm{~Pb}$ & $3.2 \mathrm{~mm} \mathrm{~Pb}$ \\
\hline $\begin{array}{c}35500 \\
(70-220) \\
20100 \\
(15-220) \\
11600 \\
(11.115) \\
9860 \\
(12-125)\end{array}$ & $\begin{array}{c}313 \\
(160-220) \\
64 \\
(9-220) \\
79 \\
(12-160) \\
48 \\
(11-138)\end{array}$ & $\begin{array}{c}9.19 \\
(160-220) \\
2.1 \\
(9-220) \\
2.0 \\
(12-160) \\
1.4 \\
(16-138)\end{array}$ \\
\hline
\end{tabular}

\footnotetext{
"Sample is (51-mm-diam, 0.51-mm-thick, 22-g) $93 \%{ }^{235} \mathrm{U}, 0.94 \mathrm{~m}$ from detector face.

b Numbers in parentheses are optimum energy windows for maximum $\mathrm{S}^{2} / \mathrm{B}$ given in keV photonenergy for $\mathrm{Nal}$ and $\mathrm{keV}$ recoil electron-energy in delector for NE-102.

'Unshielded.
} 
TABLE VII

\section{DETECTOR EVALUATION WITH SHIELDED ${ }^{238}$ U SAMPLEa}

\begin{tabular}{|c|c|c|c|c|c|}
\hline \multirow[b]{2}{*}{ Detector ${ }^{c}$} & \multicolumn{5}{|c|}{$S^{2} / B$ for Given Sample Shielding ${ }^{b}$} \\
\hline & $1.6 \mathrm{~mm}$ brass & $1.6 \mathrm{~mm} \mathrm{~Pb}$ & $3.2 \mathrm{~mm} \mathrm{~Pb}$ & $6.4 \mathrm{~mm} \mathrm{~Pb}$ & $12.7 \mathrm{~mm} \mathrm{~Pb}$ \\
\hline $127 \cdot \mathrm{mm}$ by $25-\mathrm{mm} \mathrm{Nal}$ & $\begin{array}{c}552 \\
(13.1130)\end{array}$ & $\begin{array}{c}152 \\
(210-1130)\end{array}$ & $\begin{array}{c}100 \\
(260-1130)\end{array}$ & $\begin{array}{c}47 \\
(318.1130)\end{array}$ & $\frac{12}{(318-1460}$ \\
\hline 127-mm by 51-mm NE-102 & $\begin{array}{c}205 \\
(17-857)\end{array}$ & $\begin{array}{c}78 \\
(74-857)\end{array}$ & $\begin{array}{c}53 \\
(95-857)\end{array}$ & $\begin{array}{c}27 \\
(116-857)\end{array}$ & $\begin{array}{c}7.7 \\
(131-907)\end{array}$ \\
\hline 127-mm by 102-mm NE-102 & $\begin{array}{c}243 \\
(25-857)\end{array}$ & $\begin{array}{c}96 \\
(87-857)\end{array}$ & $\begin{array}{c}68 \\
(110-895)\end{array}$ & $\begin{array}{c}36 \\
(126-895)\end{array}$ & $\begin{array}{c}11 \\
(131-895)\end{array}$ \\
\hline
\end{tabular}

${ }^{a}$ Sample (51-mm-diam, 2.5-mm-thick, $\left.104-\mathrm{g}\right){ }^{238} \mathrm{U}$ disk $0.416 \mathrm{~mm}$ from detector face.

b Numbers in parentheses are optimum energy windows for maximum $S^{2} / B$ given in keV photon-energy for $\mathrm{NaI}$ and keV electron-energy in detector for NE-102.

Unshielded.

and more uniform ver!ical response, it was rejected because of cost. The plastic scintillator systern used four $51-\mathrm{mm}$-diam by 914-mm-long rods of NE-110. NE-110 was used instead of NE-102 because of its better light transmission characteristics even though it is more expensive. However, we do not feel that it gave any significant improvement over NE-102 in this geometry. Each rod was coupled to a $127-\mathrm{mm}$ long light pipe and an RCA 4523 PMT. The total cost for these four detectors, including tube bases and

TABLE VIII

\section{OPTIMUM WINDOWS FOR 127-MM-DIAM BY 25-MM-THICK NaI AND 239PU SAMPLE ${ }^{\circ}$}

\begin{tabular}{cc} 
Sample Shielding & $(\mathbf{k e V})$ \\
\hline Bare & $13-130$ \\
$3.2-\mathrm{mm}$ brass & $13-440$ \\
$0.79-\mathrm{mm}$ lead & $320-440$ \\
$1.59-\mathrm{mm}$ lead & $320-440$ \\
$3.18-\mathrm{mm}$ lead & $320-440$ \\
$6.35-\mathrm{mm}$ lead & $320-440$ \\
$12.7-\mathrm{mm}$ lead & $13-480$ \\
$19.0-\mathrm{mm}$ lead & $13-250$
\end{tabular}

asmple $\left(9.82-\mathrm{g}\right.$ of $\left.93.81 \%{ }^{239} \mathrm{Pu}\right)$ is right circular cylinder of height $=$ diam $=9.27 \mathrm{~mm}$, canned in 0.25 -mm-thick stainless steel. voltage dividers, was about $\$ 1450$ (for NE-102), over $\$ 1000$ less than the $\mathrm{NaI}(\mathrm{T} /)$ system.

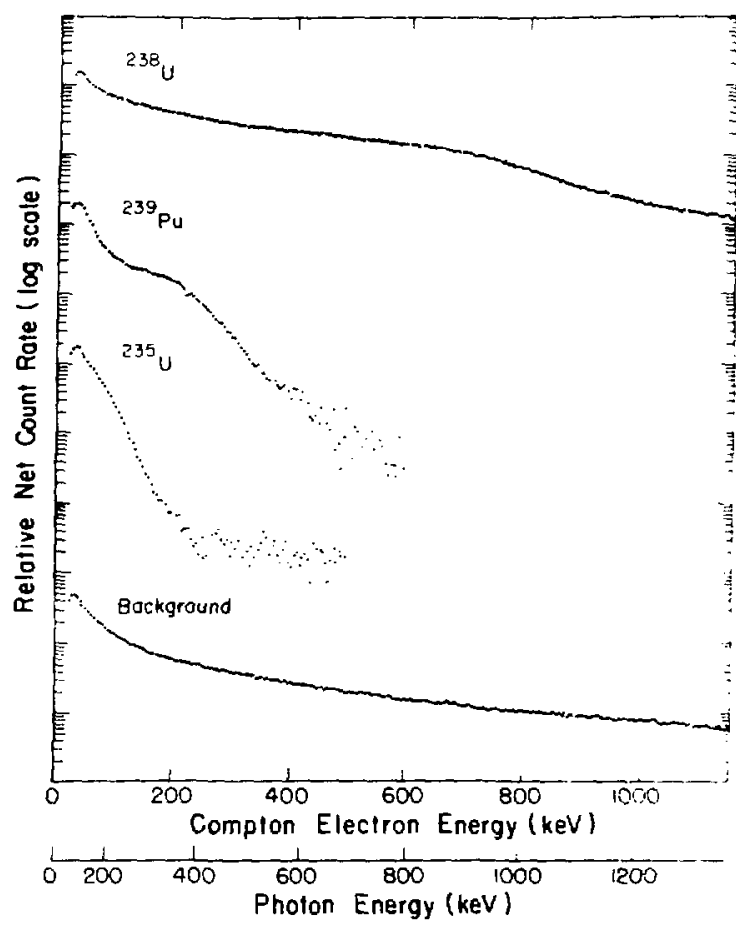

Fig. 8.

Typical pulse height spectra from a 51 -mm-diam h. 914-mm-long rod of $\mathrm{NE-102}$ plastic scimillusor. Silurces are the same as Fig. 5. 
The detector cost Srr a plastic sysiem consisting of six 127 -mm-diam by 102 -mm-thick NE-102 cylinders would be about $\$ 1700$. We felt the major advantage of the plastic scintillator should be its low cost and thus rejected this higher priced version, even though it appeared that such a system might outperform the rods.

\section{MECHANICAL STRUCTURE}

The freestanding doorway structure is constructed of four pieces of polyurethane foam, cut from two pieces $10-\mathrm{cm}$-thick by $2.44-\mathrm{m}$-long by $61-\mathrm{cm}$-wide. Provisions are also available for positive floor mounting without the floor plate shown in Fig. 9. The foam pieces are bandsawed to external dimensions, then shaped internally for the hardware with a simple rasp bit in a drill press or hand drill. An interior width of $69 \mathrm{~cm}$ was used for the Nal doorway, whereas the plastic doorway's was $76 \mathrm{~cm}$.

The assembly of the portal monitor components in the toam structure is shown in Figs. 10 and 11. After

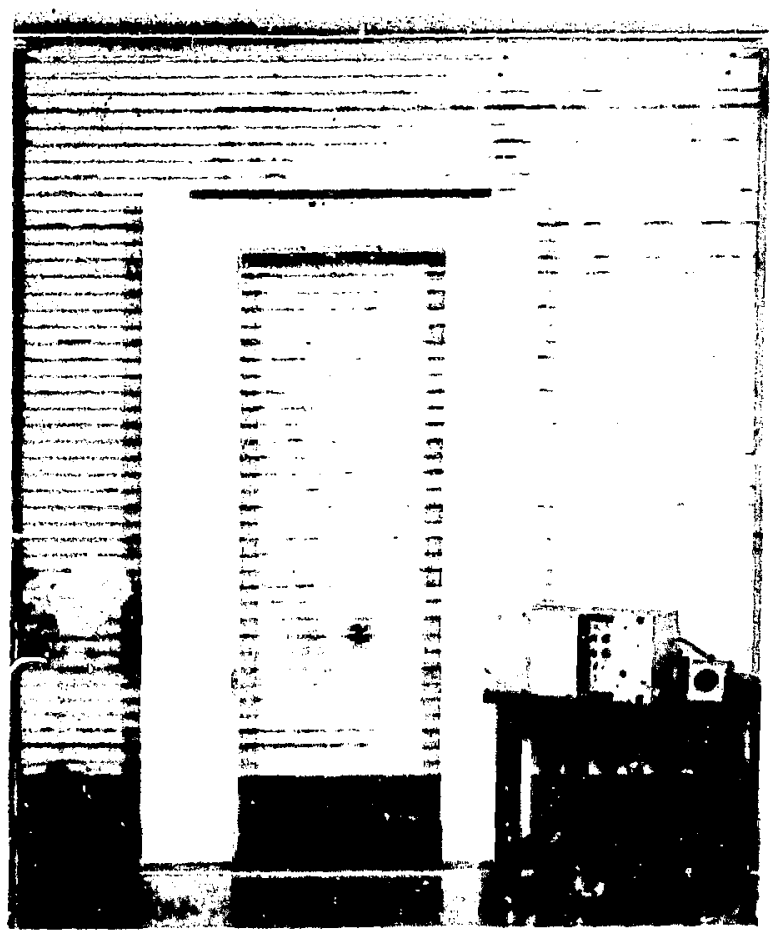

Fig. 9.

Comple'te dourwa! monisor yoroms. the equipment is sandwiched in the foam haives and padded with foom rubber to prevent mechanical shock, they are joined with epoxy resin over the fiber-glass cloth. Cable junctions are made in a metal box that mounts between the two frame halves and screws into glassed-over metal plates. Two coats of highly reflective white paint are rolled on over the glass cloth for an inexpensive but rigid, insulated package.

\section{ELECTRONIC DESIGN AND CONSTRUCTION}

\section{A. Requirements}

The electronic system was designed to minimize routine interactions beiween the inspector at the po:tal and the system by automatically updating the warning level generated from average values of the background. The only interaction required is the ap. propriate response by the inspector when a warning occurs as a person walks through the doorway.

A digital rather than analog logic system was chosen for several reasons.

(1) A digital system provides more inherent stability witil no de levels to drift.

(2) It can perform a noving average to eliminate the need to start the coust interval with a flow switch, light becm, or other sensor.

(3) It can accurrtely generate a warning level of some $\mathrm{n}$ standard deviations over a large dynamic range of counts per interval. The warning level provides proper operation over varying background count rates and allows the basic logic syslem to be used with a voriety of detector types and sizes of detector arroys. The user must modify the expected detection probability and statistical talse alarm rate if the average count per interval falls below about 30 counts, because below this value the probability of an expected count does not follow the Gaussicin dis. iribution.

We have designed a system that provides a war. ning oulput if the count $C$ in an inlerval is $C>\bar{B} \cdot n \sqrt{B}$, where $\bar{B}$ is the average background and $\mathrm{n}$ is the number of stcndard dovialions. A further design goal wrs to allow normal personnel traflic and to provide a redichon monitor thet gen continuously rathe than only when occupied. By genetcting $a$ moving avercge of the const, we sre assured that the counting intervol will spon the peck count rate when a person walks through the doorway with o souree

The ditgital logic sysem has had sevesal design changes. Two units of the tirst generation logic system wese built and tested, and extensive 


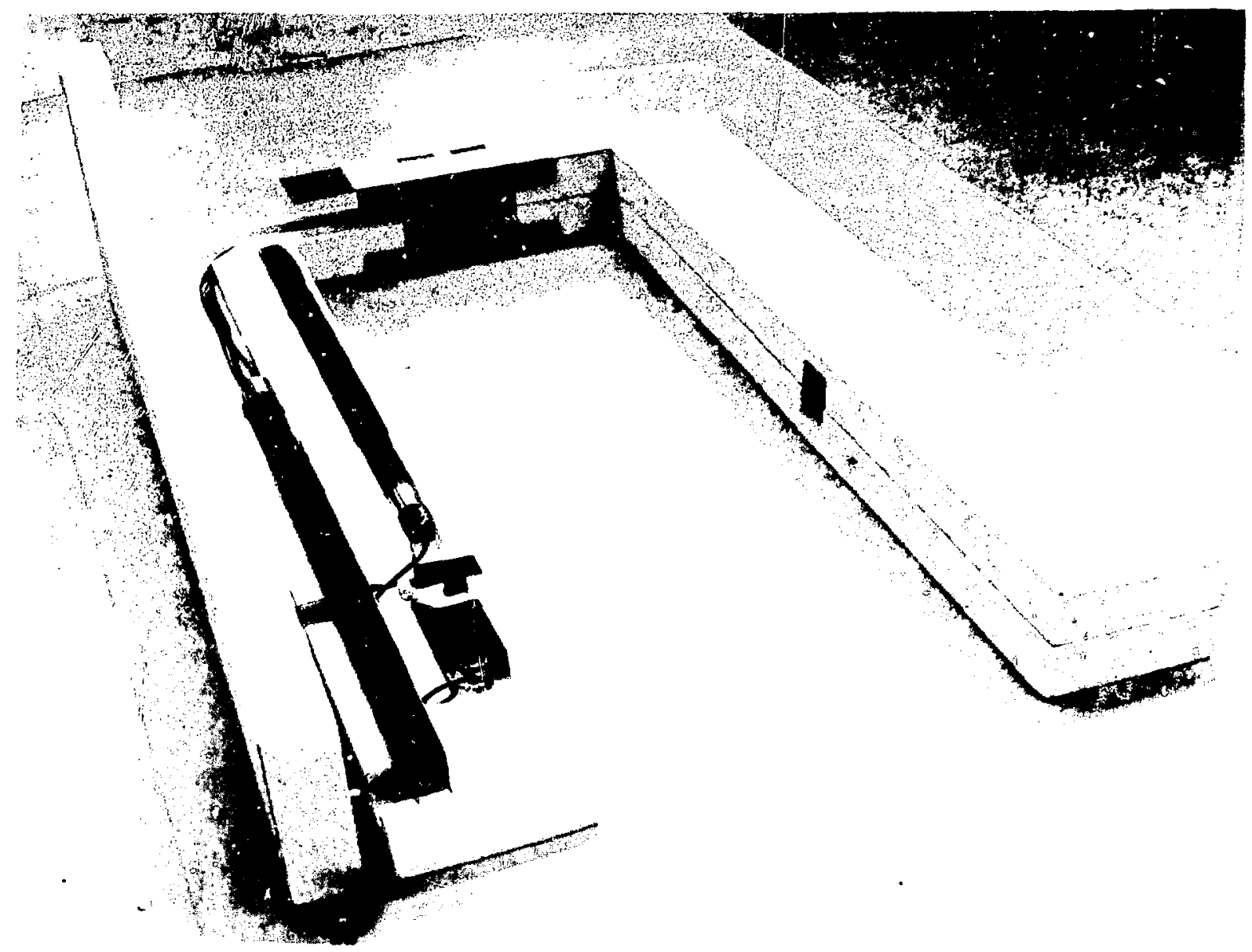

Fis. Ho.

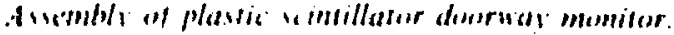

measurements on complete doorway monitors were carried oul with them. The result of these lests are discuesed later. The experience gained with this system was used to eimplify the degign and eliminate some of the problems lound during lesting. The se. cond generation logic eyolved from these im. provements, and the principles of its design are dis. cussed in this section. Labordory bench madels have been buitt, but the second generation logic has not yet been integrated into a doosway monitor system. The tirst generation ryatem is also described to il. lustrule the differences botween the two logic syotems.

\section{B. System Description}

A diagram of the doorway monitor system is shown in Fir. 12. The lour deleclors are connected to a singl, high-vollage power supply with individual detector gain adjustments made of the photomulipliez bases. Commercial photomultiplier high-vollege power supplies are satisfactory. We chose a Power Designs AEC.315B." The resultan! signals from the defectors are led through an ORTEC 113 seintillation preamplifier. Two preampliliers ate

- Although we give the specific models used in our sys'em, equicalent ones are cuailable trom other motrutuctuters 


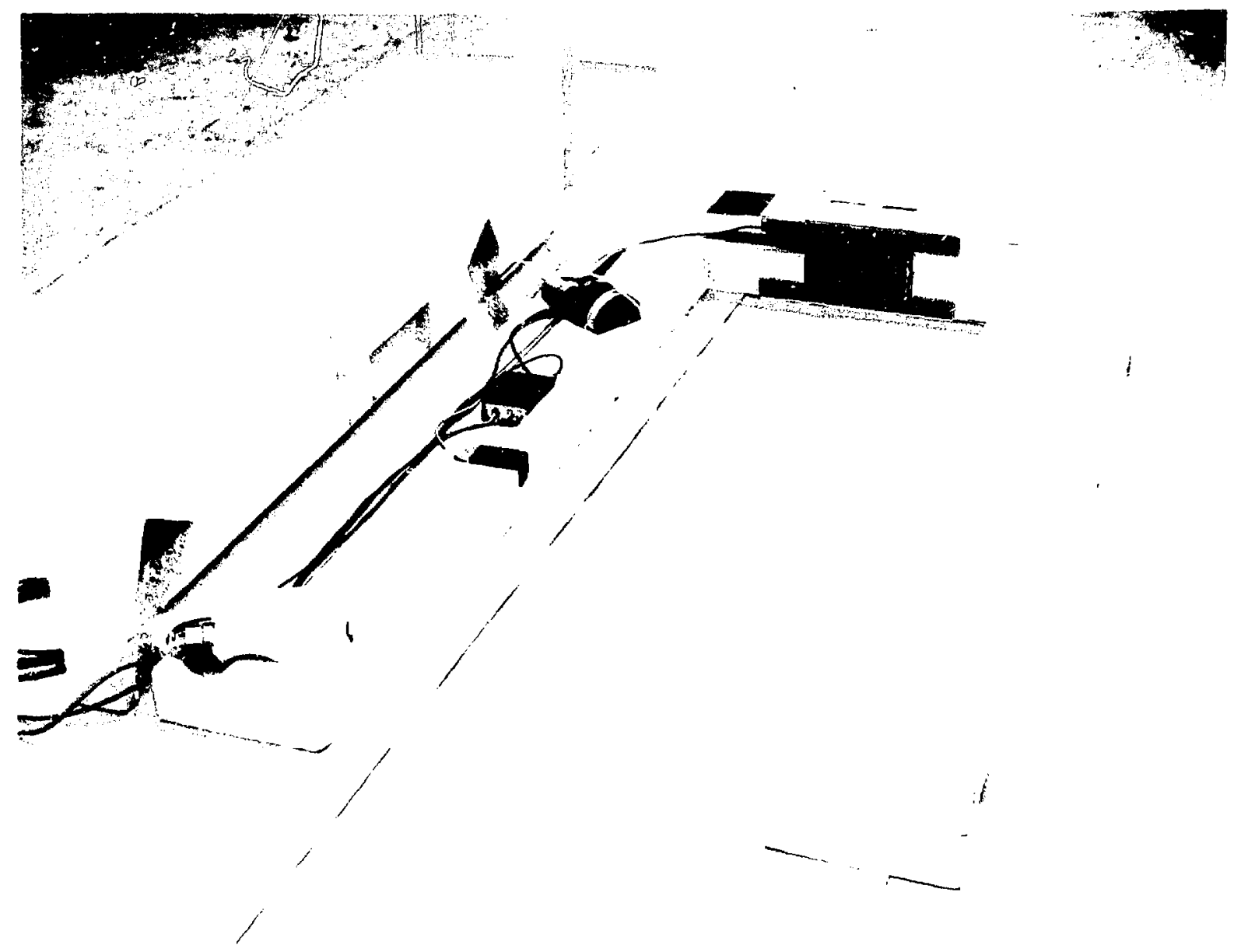

Fig. 11 .

Assembly of Nall Til doorwal monitor.

used, one on each side of " portal, each. serving two detectors. These two signals are in turn fed to an ORTEC 485 amplifier for turther amplification and shaping. The amplifier output is fed to an ORTEC 406A SCA, which has a lower level discriminator (LLD) output and a window output. These outputs are logic signals representing all detected counts that exceeded the lower level threshold and all detected counts that exceeded the lower level discriminator but did not exceed ar upper level discriminator. These logic signals are then fed into each of two channels of the LASL-designed logic module. The 406A LLD and SCA outputs had to be modified to increase the output amplitude from the normal $+5 \mathrm{~V}$ to $=+6.5 \mathrm{~V}$ to be compatible with the LASL module logic level requirements.

A light source on one side of the doorway and a phofocell positioned on the other side provide $a$ signal to the logic module, indicating that the doorway has been accupied. This signal is also fed to the logic module, which provides an output alarm signal to expose a single frame in the Kodak Analyst Surveillance camera if the count in eicier of the two channels exceeds the stored warning level by one or more counts. Alarms occurring within $1.25 \mathrm{~s}$ after the first alarm are suppressed because the camera can only take single frames at the rate of $0.8 / \mathrm{s}$. If the doorway is occupied during an alarm, then a signal will also activate a visual and audible alarm. Note that both an occupied signal and a radiation signal are required before the inspector is alerted. If an alarm occurs while the light beam is interrupted, a hole' ig circuit disables the automatic background update feature for 60 counting intervals. This allows the inspector to recheck the suspect by having him 


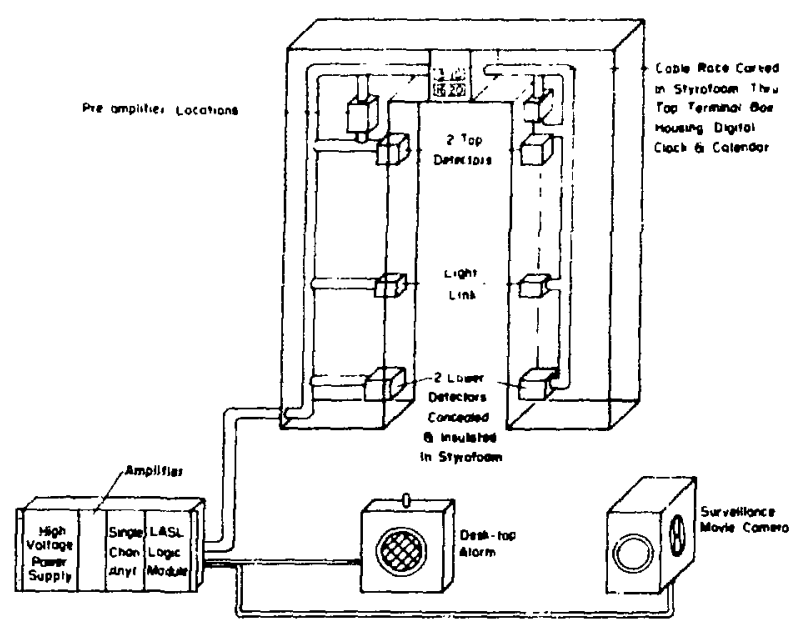

Fig. 12

Block diagram of the doorway monitor system.

pass through the monitor again against the same background, which he apparently exceeded on the first passthrough. If it is necessary to hold the suspect in the monitor, a dc inhibit feature also continuously inhibits background updating for as long as the light beam is continuously broksn.

\section{First Generation Warning Logic Module}

The first generation logic module has two channels for the two signal inputs. To describe the system shown in Fig. 13, we will follow a signal through channel one.

The incoming signal goes to the signal toggle and through a gate to the sliding-interval counter. The gate is normally open except when the system is reset. At reset the signal is inhibited until a background is stored to suppress an initial series of false alarms. At the signal toggle, the signals from channel one and channel two are alternately fed to the $\bar{B}+n \sqrt{B}$ scalers. If this count is less than an internally selectable prewired value of $\left(2^{5}, 2^{6}, \ldots, 2^{9}\right)$, a lower level warning is activated. Likewise, an upper level warning is activated if the count exceeds an in. ternally selectable prewired value of $\left(2^{10}, 2^{11}, 2^{12}\right)$.

The background signals are toggled to the warning-level generator because of the number of integrated circuits required. The warning level, consisting of the $\bar{B}$ and $\sqrt{B}$ in serial binary form, is then transferred to a buffer storage for use until it is up. dated. The accumulation period for the stored war- ning level can be internally selected from $(10,20, \ldots$. 90) $\times T$, the major count interval, and automatically updated every $(10,20, \ldots, 90) \times 2 T$. The major count interval $\mathrm{T}$ is composed of 9 subintervals $\tau$ where $\tau$ can be internally selected over a range of 0.065 to $0.162 \mathrm{~s}$ in 7 unequal increments. The conditions we have extensively used for testing the tirst generation system are $\tau=0.065 \mathrm{~s}$, background accumulate period $=30 \mathrm{~T}=17.5 \mathrm{~s}$, and $a$ background update period of $35 \mathrm{~s}$. When the $\bar{B}$ and $\sqrt{\bar{B}}$ are shifted out oi the buffer storage to the compare logic, the $\sqrt{B}$ is offset by the number of bits required to accomplish the $\mathrm{n} \sqrt{\mathrm{B}}$ multiplication.

The other route for the incoming signals to the sliding interval counter goes to a binary courting register. At the end of each subinterval $(\tau)$ the contents of this register are parallel loaded into a parallel-in/serial-out shift register. These are then shifted out into another shift register that is nine shift registers $\left(\tau^{\prime} s\right)$ long, which acts as a memory, then to a serial adder and to a gate. The gate opens with a period equal to the major counting interval $(T)$, and the adder contents are then shifted out concurrently with the same count that shifts out of the memory shift register. A bit-for-bit comparison is made to insure that no bit errors occurred in the memory shift register. The serial word coming out of the first shift register is the most recent, or $\mathrm{C}_{1+B}$; and the count coming out of the memory shift register is $C_{1}$, or the count recorded a time $9_{\tau}$ earlier. The difference $\left(C_{j+8} \cdot C_{i}\right)$ is fed to an adder and is added to the sum stored in the accumulator. The number stored in the accumulator is the moving average over the last $9_{r}$ This moving average and the generated warning level are compared in a bit-for-bit serial compare system. If the count exceeds the warning level by one or more counts in channel one or channel two, an in. ternal alarm occurs. This causes a photograph to be taken of the doorway unless another alarm occurred no greater than 1.25 s prior to the clirrent alarm, in which event the current alarm is suppresed. Assuming that the alarm is not suppressed and the doorway is occupied, then an audio and visual alarm is ac. tivated for the inspector, and the background update is inhibited. This locks the background at the value prior to the alarm and permits the inspector to have the indiridual walk through the doorway soveral times without changes in the stored background

During the dexign, conatruction, checkout, and field lests of the systom, eaveral doficiencies in this first generation oystem became evidont. The warning level, $\bar{B}+n \sqrt{B}$, is not updatod an often as desirable to accommodate a fluctuating background because only one warning-level generation symem eerves the 


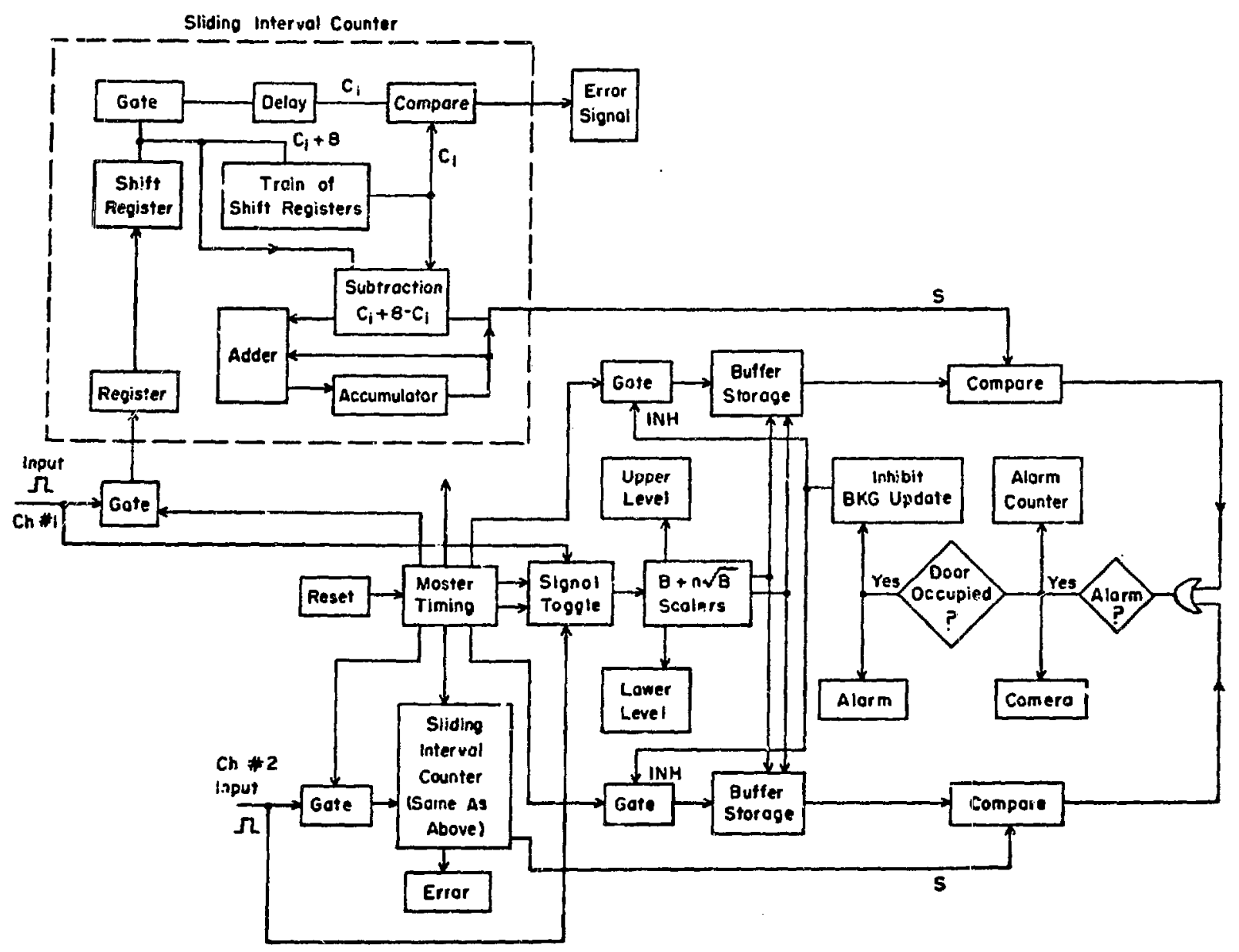

Fig. 13.

Block diagram of the doorway monitor's first generation warming logic module.

two channels. The upper and iowe: level count warning feature has been useful, but a limitation results from having this feature in the common $\bar{B}+\Delta \sqrt{\bar{B}}$ scalers. The lower level count monitors the higher count channel with less sensitivity, and the uppor level count monitors the lower count shanal with less sensitivity. These problem can bo alloviaied by having a $+n \sqrt{B}$ scaler for each channel.

Another problem that became evident regarded the generation of the moving average through the use of an accumulotor. Any orrors thist might bo induced by exiernal if noie or an exisendingly high count rate, which caunes the accumulator to oyartlow, will be reicained until the eytem is reset. This can be corrected by a systam that dees aot use an aceurvulatoz.
The audible and visual warning signals and the camera-activation signals have performed as desired.

\section{Second Generation Warning Logic Modulø}

To simplify the design and eliminate some of the deficiencies noted in Soc. VI. C, a bench model of a new system was designed and built for doorway monitor applicatione. The production of the esuare root in both the tirnt and second geaneration ryitems is based upon priaciples precentsd in the work of Rao et al and Taylor of al. ${ }^{10}$.

A diagram of a binary rate divider is shown in Fig. 14. Astume a number $D$ is atored in the diviso: 


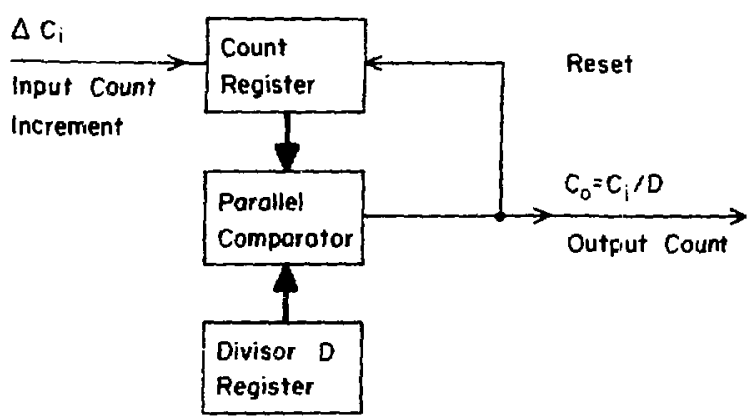

Fig. 14.

Block diagram of binary rate divider.

register, and the count register is initially at zero. The input counts are counted until the contents of the count register equal $D$. At that time the comparator emits a pulse that resets the count register and provides an output pulse. The output count rate $C_{0}$ is then equal to $C_{i} / D$.

Connect the divisor register to the output count rate as shown in Fig. 15. The inpul count in a certain time is

$$
C_{8}=\sum \mathrm{AC}_{1} .
$$

In this time, the output $\Delta C_{0}$ is summed in the divisor register giving

$$
c_{0}=\sum \Delta C_{0}
$$

Thus, the output count increment is

$$
\Delta C_{0}=\frac{\Delta C_{1}}{C_{0}} \quad \text { or } \quad \Delta C_{1}=C_{0} \Delta C_{0} \quad .
$$

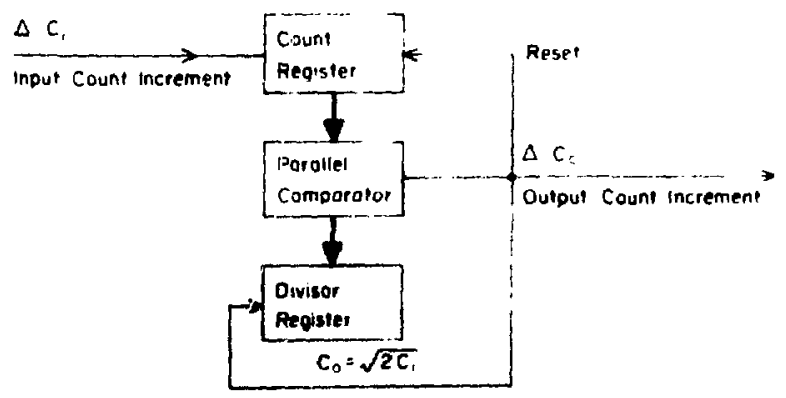

Fig. 15.

Bloch diagram of a binary rate divider commested to provide a syuare-ronof extraction.
If we consider these as infinitesimal increments and integrate, we have

$$
\begin{aligned}
& \int_{0}^{C_{1}} d C_{1}=\int_{0}^{c_{0}} c_{0} d C_{0}, \\
& \text { and } \\
& c_{0}=\sqrt{2 C_{1}} .
\end{aligned}
$$

and

Thus the square root of twice the input count is stored in the divisor recister. If we then modity the circuit in Fig. 15 to that shown in Fig. 16, by dividing by two in the input count line

$$
c_{0}=\sqrt{C_{1}} \text {. }
$$

Thus we have a simple means of generating the square root of the count in an interval. This does require that an initial condition of a one be stored in the divisor register and that the divide by two and count register be reset to zero. The circuit, similar in principle to the first generation logic system, is much simpler and requires fewer integrated circuits. The first generation system did not reset the count register and therefore required a number of storage latches and adders to predict the next count register number, having a square root one greater than the current square root.

Next consider the generation of $\alpha$ moving average shown schematically in Fig. 17. The object is to sum the counts over a major interval $T$ and generate $a$ new sum every 1. Analysis of experimental dota (see Sec. IX. A) has shown that $t=T / 4$ is about optimum. Consider a count register as shown in Fig. 18. which is parallel loaded into a parallel-in/serial-out

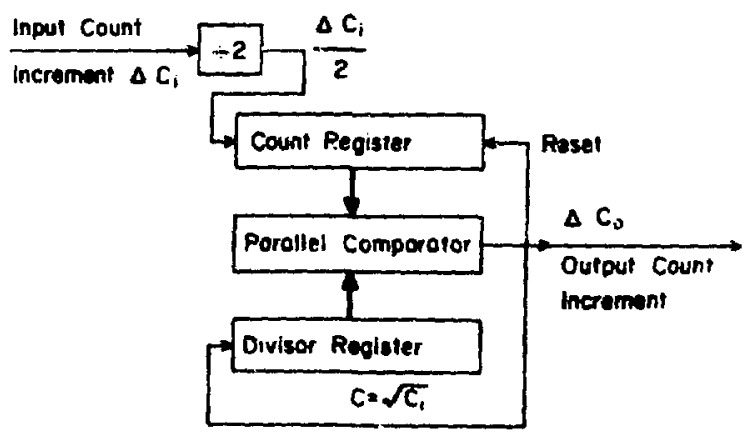

Fig. 16

Stpare-runer logic. 


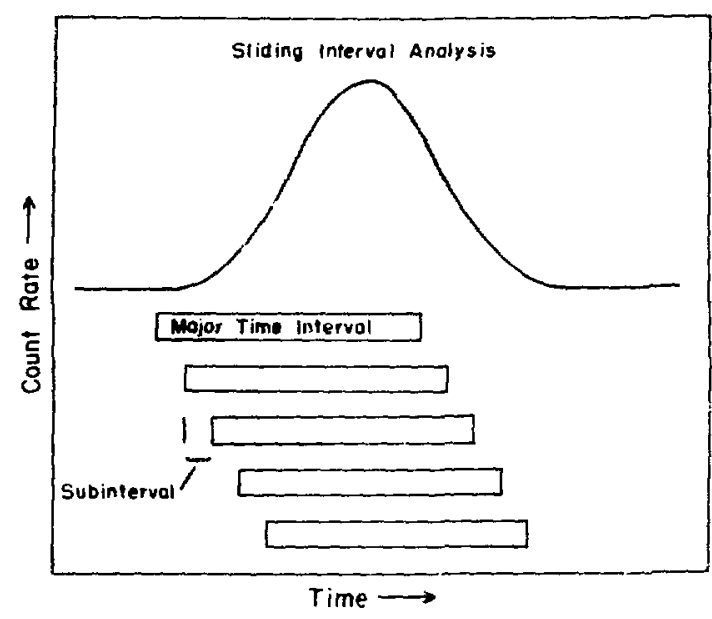

Fig. 17.

Sliding-interval techntique.

shift register. After loading into the shift register, the contents are shifted out with an appropriate shift train into a serial adder and into a second shift regisier. Concurrently the output of this shift register is fed to the other input of the serial adder. In the same manner the sum from the adder is added to the contents of the third shift register; and, likewise, this resultant sum is added to the output of the fourth shift register. The final output sum is the moving average of four subintervals.

This system is also similar to the first generation system except it does not have an accumulator. Thus no subtractions are required and no problems of accumulator overflow exist. We accomplished a binary subtraction is the first system by inverting the sub. trahend and adding it to the minuend; the resultant

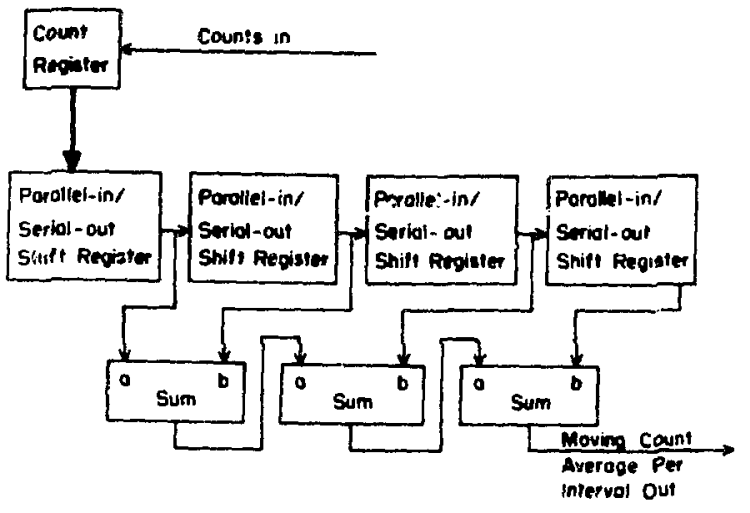

Fig. 18.

Minving average counter. number was the difference minus one. The difference was then obtained by adding one to the resultont number.

The moving average count must be compared with the warning level. The first generation system compared the two numbers with separate, exclusive ORs, NANDs, etc. In the second-generation system we used a serial adder and one inverter, illustrated in Fig. 19. The carryout of the output will remain high if C $>$ B. For example, assume that

$$
B=5_{d O 0: D A}=101_{b: A A T,},
$$

and

$$
C=6_{d a c t a t}=110_{b} \operatorname{ang} y .
$$

Now $\overline{\mathrm{B}}=010$ and $\overline{\mathrm{B}}+\mathrm{C}$ would be

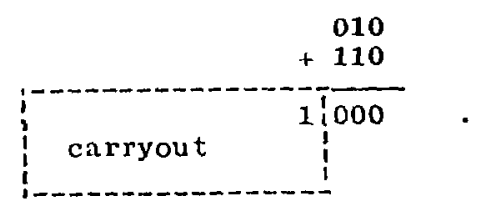

The carryout is high. Now if $C=4$, then $\bar{B}+C$ is

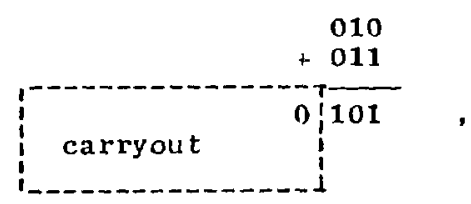

and the carryout is low. Likewise, if $C=5$ the carryout is also low. A warning is produced from this comparison if $\mathrm{C}>\mathrm{B}$ by one count. Note, however, that we can use only the carryout, not the complete output.

The other items needed in the warning generation are the multiplication of the square root of the average background by $n$, the addition of $n \sqrt{\bar{B}}$ to the average background, and the generation of a serial word. One may, of course, easily multiply a binary

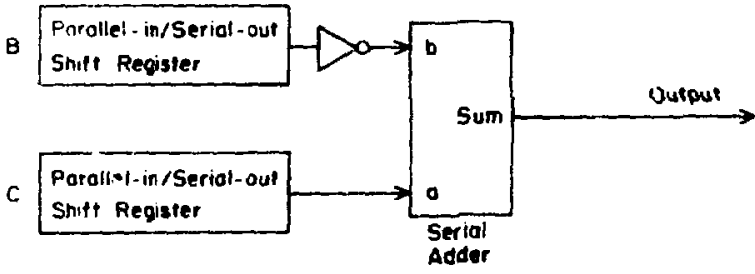

Fig. 19. Comparison kgic. 
number by shifting the parallel load into the parallelin/serial-out shift registers. In Fig. 20 the separate building blocks are put together.

\section{FALSE ALARM PROBABILITY}

\section{A. Calculational Method}

When the sliding-interval technique was first proposed, the effects of correlated false alarms on the total false alarm rate were questioned. The calculations described in this section were performed to analyze this effect. The entire discussion in this section relates to statistical false alarms that are registered only internally in the doorway monitor system. In adouition, occupancy is required before audible and visual signals are given.

Suppose the expected background count in a counting interval $T$ is $\bar{B}$. At the end of each consecutive counting interval, the actual number of counts accumulated $C$ is compared with $\bar{B}$, and an alarm occurs if the net count $C-\bar{B}$ exceeds some selected alarm level.

The ambient background count rate is described by the integer Poisson distribution, which is characterized by one parameter, the value $\mathrm{m}$. The expected background count in $T$ is used as the mean value, and the alarm level is chosen as some number of standard deviations $(\sigma=\sqrt{\mathrm{m}})$. The alarm probability for the consecutive interval case can then be readily determined by evaluating the Poisson dis. tribution probability for variations from the mean of this number of standard deviations.

The first problem in using the sliding-interval method is to determine how these alarm probabilities coinpare with those for the consecutive-inlerval method for the same total counting time. To evaluate alarm probabilities for the sliding-interval case, the background counting procedure was simulated by

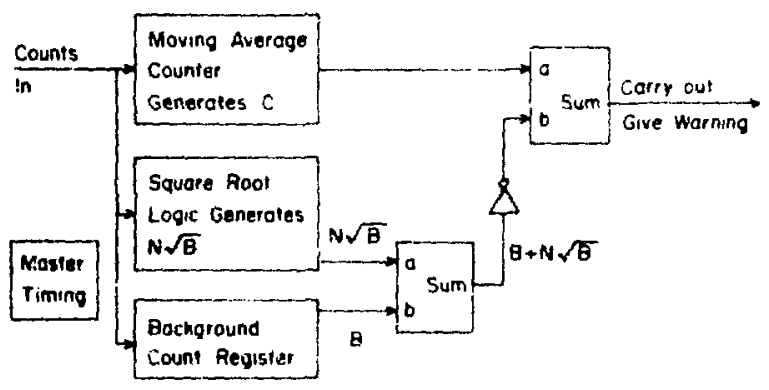

Fig. 20.

Siste'm warning block diagram. using Monte Cario sampling methodis. For each subinterval $r_{i}$, the background count $C_{i}$ is determined by sampling from the Poisson distribution using computer-generated random numbers. The sampling algorithm by $\mathrm{Knuth}$ "ll was used in these calculatuas. With this sampling method, alarm probabilities were calculated for both the consecutive and sliding-interval methods, using 5, 10 , and $20 \mathrm{~T}$-subintervals per $\mathrm{T}$-interval with alarm levels of $\left(C_{i}-B T^{\prime}\right)>2,3$, and $4 \sigma$. All calculations are based on a fixed background of 1000 counts per time interval T. This background was not considered to be statistically variable. These calculations showed that for a given alarm level, the alarm probabilities are the same for the sliding-interval and consecutiveinterval methods and are independent of the number of subintervals. Because there are n 7 -subintervals per T-interval, the sliding-interval method makes ntimes the number of alarm tests as the consecutiveinterval method. The equal probabilities mean that the number of alarms occurring with sliding intervals is n-times the number with consecutive intervals for the same total counting time, an obvious disadvantage of the sliding-interval technique.

\section{B. Results}

Alarm probabilities for 2-, 3-, and 4-a deviations calculated for the sliding-interval method are given in Table IX. Statistical uncertainties and computational uncertainties associated with application of the sampling algorithm result in errors less than $\pm 10 \%$ in the calculated probabilities. This is verified by comparing these calculated probabilities to the probabilities expected from the normal approximation to the Poisson distribution valid for this cose.

A single large-amplitude spurious signal can result in $\mathrm{n}$ alarms, because this single large signal will be included in n alarm tests. This causes an erroneously high number of alarms to be detected. Several closely spaced spurious signals will result in additional false alarms. To reduce the occurrence of these extra alarms, a sliding-interval detection method with count suppression can be used. When an alarm is defected, the data accumulation is suppressed for the next a subintervals, then the counting and alarm lesting continues in the usual manner. This technique will eliminate the next $\mathrm{n} \cdot \mathrm{l}$ alarms that would otherwise be caused by ihe single large count. The count suppression will also result in the second of two true alarms not being counted, if the two occur in a time interval shorter than the counting interval $n \boldsymbol{n}=\mathbf{T}$. 
TABLE IX

\section{FALSE ALARM PROBABILITIES FOR SLIDING-INTERVAL METHOD}

\begin{tabular}{|c|}
\hline Alarm Lrevel \\
\hline $\begin{array}{l}2 \sigma \\
3 \pi \\
4 \sigma\end{array}$ \\
\hline
\end{tabular}

\author{
Cclcizlated False Alarm \\ Probability
}

0.022

0.0014

0.000034

\author{
Expected Probability \\ Normal Distribution
}

0.0227

0.00135

0.0000317
Alarm probabilities for the sliding-interval method with suppression were calculated using the same sampling techniques discussed previously. Whenever the normal distribution provides a sufficiently accurate approximation to the Poisson distribution, sampling with the normal distribution will reduce computing time by a factor of about 5 . The normal distribution sampling algorithm ${ }^{10}$ is inherently faster than the Poisson algorithm. Alarm probabilities for the sliding-interval method with suppression were computed by sampling from normal distribution and are given in Table $X$. These probabilities are a function of the number of subintervals, whereas the values without suppression (Table IX) are independent of the number of subintervals.

Uncertainties in these alarm probabilities vary from $\pm 5 \%$ at $2 \sigma$ to about $\pm 20 \%$ at $4 a$. Figure 21 compares alarm probabilities with suppression to the corresponding probatilities without suppression. The ratio of probability with suppression to probability without suppression is shown as a function of alarm level. For a given number of subintervals, the probability with suppression approaches the probability without suppression as the aiarm level increases. This is expected, beccuse fewer alarms occur at higher alarm levels. Less chance exists for a second alarm to occur within the interval $n_{r}=T$, which is the necessary condition for suppression. $A$ similar effect explains the decrease in probability ratio for a given alarm level as the number of subintervals increases. With a larger number of subintervals, the chance for more than one alarm to occur is greater within the interval $\mathrm{n} r=\mathrm{T}$, hence suppression is more frequent than with a smaller number of subintervals. For conditions similar to those we have extensively vsed in the first generation logic module, (that is, $\sigma=4$, and suppression of 9 subintervals) the effect of suppression as shown in Fig. 21 is about a $20 \%$ reduction in the false alarm rate.

\section{TABLE X}

\section{FALSE ALARM PROBABILITIES FOR SLIDING-INTERVAL METHOD WITH SUPPRESSION}

\begin{tabular}{ccc} 
Alarm Level & Subintervals, $n$ & False Alarm Probability \\
\cline { 2 - 3 } $2 \sigma$ & 5 & 0.0117 \\
& 10 & 0.0073 \\
20 & 0.0041 \\
$3 \sigma$ & 5 & 0.00095 \\
& 10 & 0.00065 \\
& 20 & 0.00040 \\
$4 \sigma$ & 5 & 0.000024 \\
& 10 & 0.000017 \\
& 20 & 0.000013
\end{tabular}




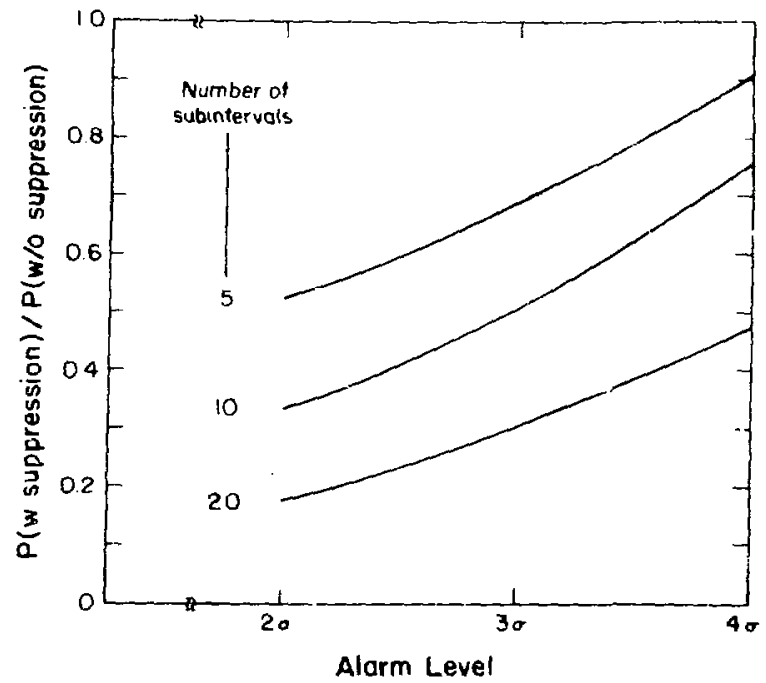

Fig. 21 .

In the first-generation logic module built for the two prototype doorways, nine 65-ms $r$ subirtervals make up one 585-ms $T$ interval. The alarm sampling rate per hour is therefore $3600 / 0.065=55385$. For $a$ $4 \sigma$ alarm level the hourly alarm rate per channel expected from background statistics alone would then be $55386 \times \mathrm{P}(4 \sigma)$. Taking $\mathrm{P}(4 \sigma)$ from Table $\mathrm{X}$ to be $3.17 \times 10^{-5}, 1.76$ false alarms $/ \mathrm{h} / \mathrm{ch}$ are expected. However, the $\mathrm{P}(4 \sigma)$ value from this probability table is not proper, because the value of $B$ used for the background comparison check changes each time the background is updated. B is not a constant, as was assumed in the previous calculations.

To evaluate further this effect on the false alarm rcte, additional calculations were performed that more realistically mocked up the operation of the first generation logic module. The logic module simulation code used a Monte Carlo normal distribution random number generator to produce the required samples. These were accumulated, as in the first generation logic circuil, into 9 sample sums and 270 sample background sums. The program followed the single-channel circuit logic in updating sample sums by dropping the earliest entry when adding the next one and by replacing the background every 540 samples with a new one. The test level used was $4 \sigma$, and resultant $\mathrm{P}(4 \sigma)$ for $3.25 \times 10^{6}$ samples was found to be $2.8 \times 10^{-5}$. The calculated statistical false alarm rate is then $55385 \times 2.8 \times 10^{-5}=1.55 / \mathrm{h} / \mathrm{ch}$.

The false alarm rate was also determined experimentally for the unoccupied doorway by tallying false alarms during periods when the background was known to be free of the fluctuations caused by

normal research activity at the site. The NaI system was monitored for a period of $385.5 \mathrm{~h}$ during which the alarms in the two-channel logic module cccurred at a rate of 3.30 per $h$. The plastic system inad an intermitlent defect whish tended io cause spurious alarms, so the period of normal, quiet operation was only $84.5 \mathrm{~h}$. During this time the rate was 1.45 per $\mathrm{h}$ for the single channel used. Thus the false alarm rate for the first generation logic appears to be a nominal 1-1/2 per channel per $h$ at a $4 a$ level. The audible alarm rate from this source would, of course, depend on the fraction of the time the doorway is occupied.

\section{SYSTEM PERFORMANCE TESTS}

\section{A. Sliding-Interval Parameter Optimization}

The first generation logic module was designed and constructed before we had determined the best values for the number of subintervals and the major interval time. The following discusses the procedure used to fix the values of these parameters. The results were used in the design of the second generation logic module.

To determine the ideal major counting interval and the optimum number of subintervals for the logic package, measurements were made during simulated usage of the unit. These measurements were subsequently analyzed with a variety of parameters to determine the optimum values of the subinterval number and the major counting interval.

The data were collected using both doorwoys with sources and source locations, which resulted in a near $50 \%$ detection probability for the existing first generation logic module parameters. The procedure used was to multiscale the SCA output as the doorway was repeatedly traversed by a sourcecarrying individual. Subsequently, a computer program that simulates the logic module operation was used repeatedly to examine the data while varying the major interval time, number of subintervals, and $n \sigma$ detection level. A constraint on the parameter variation was that the false alarm rate from statistical fluctuations should remain constant. That is, as the number of subintervals increased, $\mathrm{n} \sigma$ was also in. creased to achieve the identical statistical false alarm rate.

Figure 22 shows the results used to determine the optimum counting interval. The number of alarms detected is plotted against count interval, and a maximum is clearly shown at $0.8 \mathrm{~s}$. Similar plots at different $\mathbf{n} \sigma$ detector levels show similar results. Figure 23 shows the results for the number of alarms 


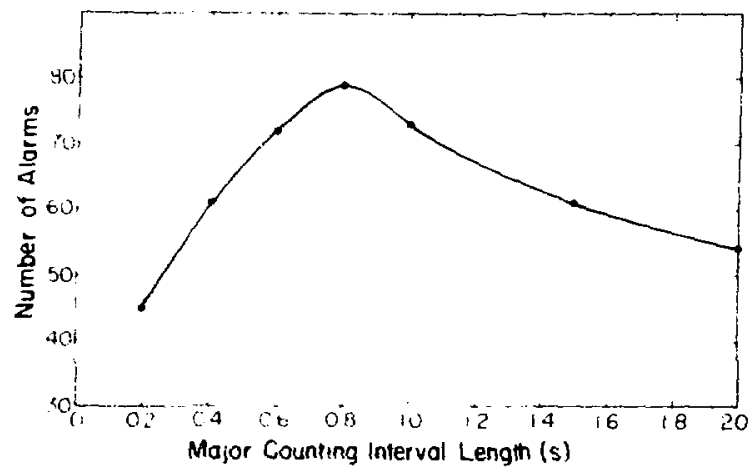

Fig. 22.

Viumber of alarmis detected vs counting inserval. Th' number of subintervals was fixed at 4 and $a$ oo detection criterion was used.

with a 1 -s counting time as the number of subintervals is varied. With the addition of the first few sub. intervals an immediate increase of about $30 \%$ results atter which no advantage is realized from additional subintervals. In fact, using more than the optimum number of subintervals increases the false alarm rate at $a$ fixed detection level, which is, of course, undesirable.

The optimum parameters for this doorway geometry are an 0.8-s counting time and 4 to 6 subintervals. These parameters (especially the major count interval) would vary for different doorway sizes.

Whereas the nine subintervals used by the first generation logic module is clearly nonoptimum from a false alarm standpoint, the 0.585 -s major count in. terval is not too far from the 0.8 -s best value. The se-

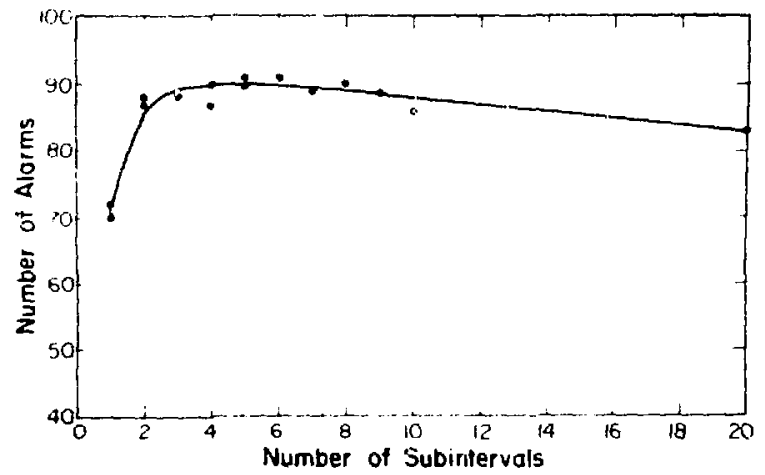

Fig. 23.

Number of alarms detected is the number of subintervals in a $1-s$ count interval The false alarm rate is held constant resulting in an no variation from $3.39 \sigma$ to 4.140 over the curve. cond generation logic can be set at the optimum values of a 0.8-s major interval and four subintervals.

\section{B. Detection Sensitivity Measurements}

To be able $r$ give an indication of the minimum quantity of enriched uranium or plutonium that cars be detected by the portal monitor, several parameters must be considered and detined. First, the confidence level must be decided. Values of $50 \%$ or $95 \%$ confidence are commonly used. We have chosen $50 \%$ lor convenience in the evaluation. Thus the mass raoted is the minimum quantity that would be sersised by the monitor on an average of one-half of the passages.

Next, one must consider the way the source is transpor'ed through the doorway. A person's speed as he passes through the portal can be expected to vary from hesitation in the portal to a very fast walk. Presumably, in actual use, an individual would be restrained from running by the attendant. Rather than attempting to average the range of sensitivities corresponding to walking rates, we left it to the person carrying the source to walk at an average pace. The test and evaluation data therefore were acquired at walking speeds that varied over values considered average by the perscnnel involved.

The position of the source in the doorway is also important because of the spatial variatior in portal sensitivity. Figure 24 shows measured count rate profiles in the center plane of each doorway. The protiles demonstrate the differences in sensitivity of the two doorways. The sensitivity also varies from side-to-side in a horizontal plane; however, sensitivity generally increases toward the sides of the doorway in any horizontal plane. The position of the

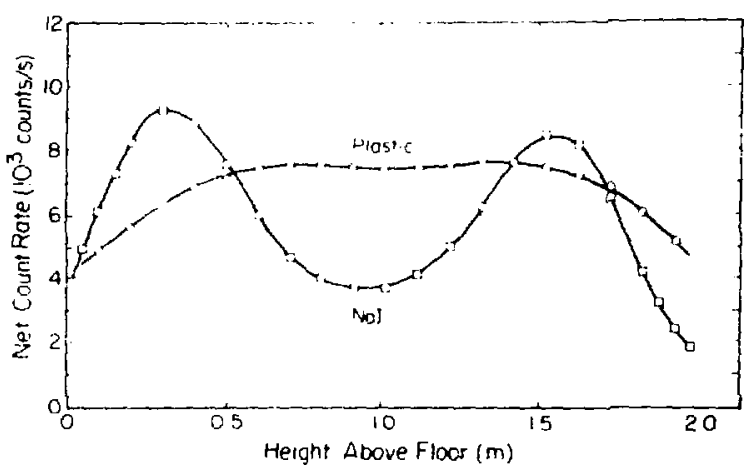

Fig. 24.

Count rate profile measured in the center vertical plane of each doorway using a $21-\mathrm{g}{ }^{235} \mathrm{U}$ disk source. 0.5-mm-thick. 
source on the body is another important factor. The rate of passage of the source can vary, for example, by holding a source in the hand and rapidly swinging the arm through the portal. We have chosen to place the source on the body in a realistic manner; that is, we do not consider the source in the hand with the arm outstretched overhead; we do not consider throwing the cource through the doorway; and we eliminate other unusual acts, all of which are unlikeIy to take place at an attended station. We chose to determine the sensitivity for four positions on the body, which we felt are likely hiding spots and are well distributed over the portal aperture. These positions were the top of the head, shirt pocket, side pants pocket, and the inside side of the shoe. The minimum sensitivity areas of both doorways are well covered by this distribution, and an average of the sensitivity for the four positions will allow comparison between the two doorways.

The sources used to determine the doorway sensitivity must have a well-known composition, since the composition can affect the gamma-ray activity. The source geometry can also affect the results of testing, because self-absorption in the source is imporiant at the gamma-ray energies considered here. The composition of our sources was chosen to represent weapon-grade material in the case of ${ }^{235} U$ and ${ }^{239} \mathrm{Pu}$, and depleted uranium for ${ }^{238} \mathrm{U}$. Isotopic analyses are shown in Table XI. The ${ }^{235} \mathrm{U}$ analysis shown here for the cylinders is probably similar to that for the few noncylindrical 235 sources used. The source geometry we chose to use is a cylinder with height equal to diameter. Self-absorption for such geometry is nearly as great as for a sphere, but the geometry is much easier to fabricate. The source set used is listed in Table XII, and count rate daia measured with a plastic scintillator rod for the ${ }^{235} \mathrm{U}$ cylinder set are shown in Fig. 25. The slope of the curve drawn through the points in Fig. 25 is 0.678 , which indicates the gamma-ray signal is proportional to (mass) ${ }^{0.678}$. This exponent agrees with the $2 / 3$ power mass dependence expected for a surface crea source. Thus the self-absorption is very important in ${ }^{235} \mathrm{U}$. Further evidence is shown in Fig. 25 by the points plotted for other source geometries used for the doorway monitor evaluations. Such extended sources proairce a signal as much as a factor of 9 larger than would be expected for a reasonably compact source geornetry.

In the case of ${ }^{239} \mathrm{Pu}$ there is an additional consideration, because $\beta$ decay of ${ }^{241} \mathrm{Pu}$ produces ${ }^{241} \mathrm{Am}$, which decays writh emission of a $60-\mathrm{keV}$ photon. The ${ }^{241}$ Am activity becomes the predominant feature of the ${ }^{239}$ pu gamma spectrum with time. The gamma activity for ${ }^{239} \mathrm{Pu}$ as a function of age is primarily the sum of the curves shown in Fig. 26. Any comparison of our ${ }^{239} \mathrm{Pu}$ sensitivity measurement would have to consider the efficiency of the unit at 60 $\mathrm{keV}$ and the age of the ${ }^{239}$ Pu sample.

Other factors to be considered are the variable parameters in the logic module and electronios package. The two important ones are the no detection levei and the SCA windows. The no level was set at $n=4$ for both doorways; $n=5$ was used for one set of measurements only on the $\mathrm{NaI}$ doorway. The SCA windows were set differently for ${ }^{235} \mathrm{U}$ and ${ }^{239} \mathrm{Pu}$ to define the optimum energy range for each. The energy range determined for each material is shown in Table XIII; the energies given for the olastic detectors are approximate because of the limited resolution of the detector. The corresponding background count rates and dose rate are given for scaling to different radiation background levels. If both ${ }^{239} \mathrm{Pu}$ and ${ }^{235} \mathrm{U}$ were to be detected simultaneously at the same station, a compromise

TABLE XI

MINIMUM SURFACE AREA CYLINDEFS ISOTOPIC ANALYSIS (ATOM \%)

MASS NUMBER

$\begin{array}{cccccccccc}\text { Sample } & \mathbf{2 3 4} & \mathbf{2 3 5} & \mathbf{2 3 6} & \mathbf{2 3 7} & \mathbf{2 3 8} & \mathbf{2 3 9} & \mathbf{2 4 0} & \underline{\mathbf{2 4 1}} & \underline{242} \\ { }^{235} \mathrm{U} & 0.998 & 93.26 & 0.421 & \ldots & 5.32 & \ldots & \ldots & \ldots & \ldots \\ { }^{238} \mathrm{U} & 0.0006 & 0.202 & 0.0032 & \ldots & 99.79 & \ldots & \ldots & \ldots & \ldots \\ { }^{239} \mathrm{Pu}^{\mathrm{a}} & \ldots & \ldots & \ldots & \ldots & 0.012 & 93.81 & 5.81 & 0.349 & 0.022\end{array}$

${ }_{241} \mathrm{Am}: 27 \mathrm{ppm}$ on $8 / 22 / 73$ 
TABLE XII

HEIGHT = DIAMETER CYLINDRICAL SAMPLES

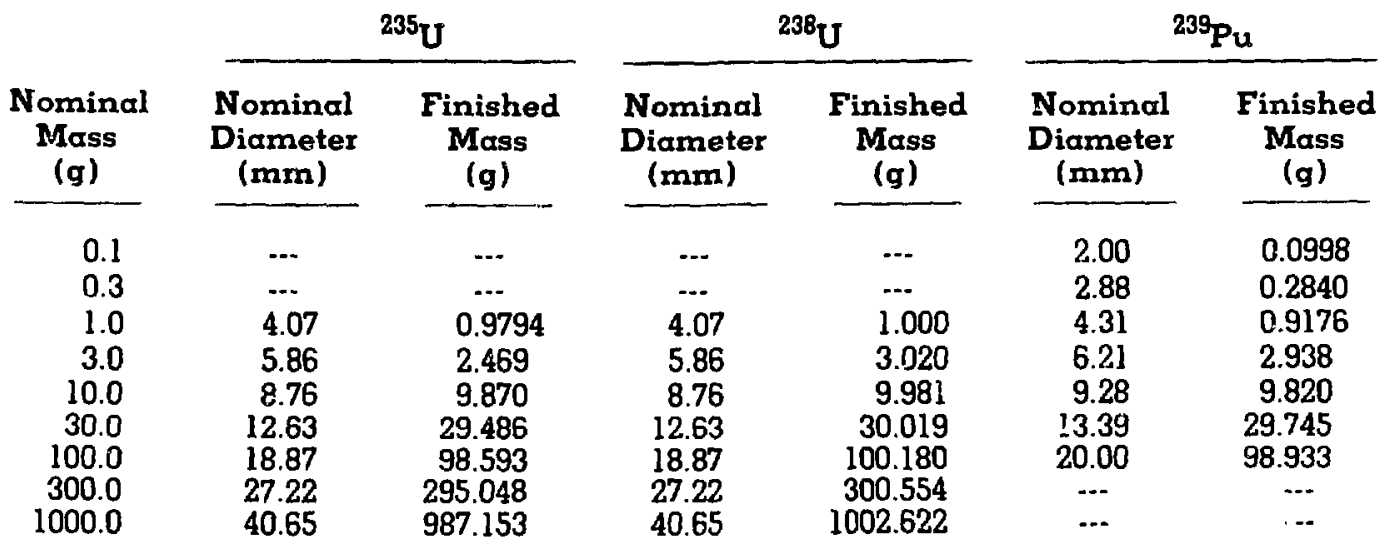

window would have to be used. We have not investigated this in detail, but the window would probably turn out to be 0 to $450 \mathrm{keV}$ jor both isotopes, or a 50- to 220-SCA window for ${ }^{235} \mathrm{U}$ with the LLD output of 50 to $\infty$ being used in the second channel for ${ }^{239} \mathrm{Pu}$.

The usual procedure to determine the detection efficiency for a particular source was to walk through the doorway 20 times with the source in each of the

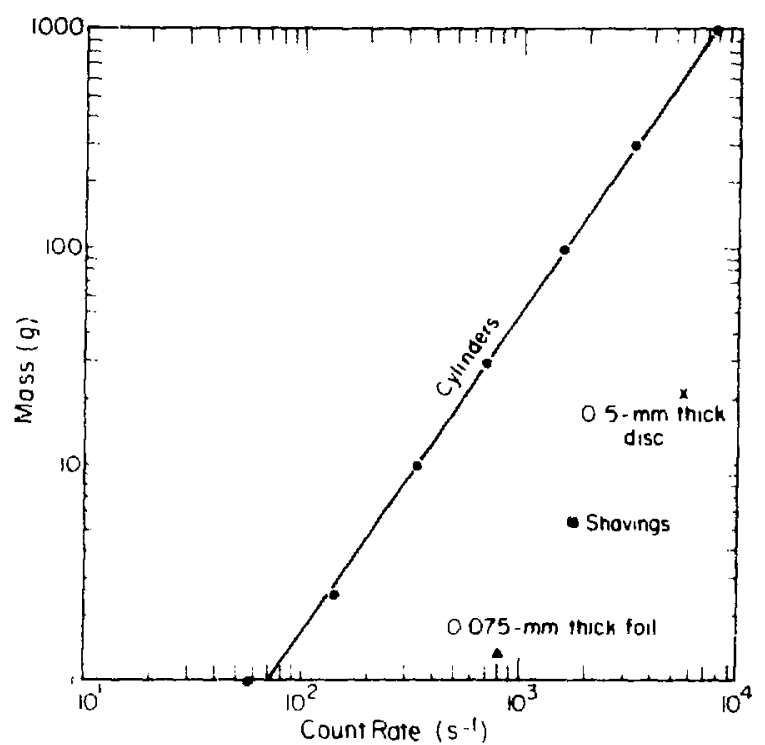

Fig. 25.

Count rate us mass for the ${ }^{235} \mathrm{U}$ cylinder sample set. Slope of the straight line is 0.678 indicating a

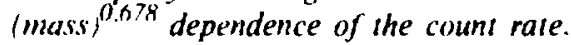

positions mentioned for a total of 80 passes. Bare source means the sourca was encapsulated with a minimum amount of plastic material, except for plutonium, which was encapsulated in $0.025-\mathrm{mm}$ stainless steel. Background during testing was about $25 \mu \mathrm{R} / \mathrm{h}$. The results are shown 2 Tables XIV, XV and XVI.

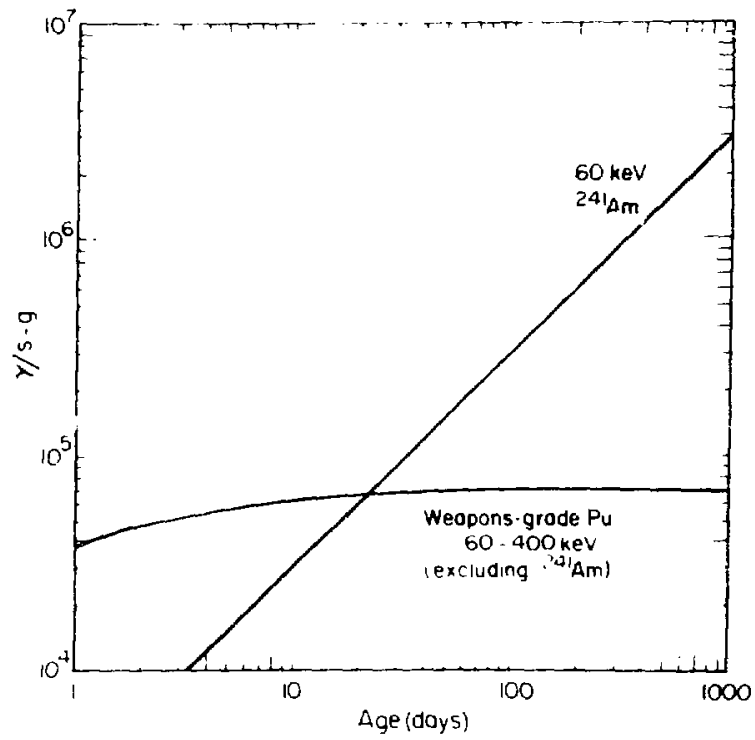

Fig. 26.

Gamma activity of ${ }^{30} P$ Pu as a function of age. The source activity is the sum of wo curves, and the $24 \mathrm{Am}$ component becomes the dominant feature afier a few weeks. 
TABLE XIII

\section{ENERGY WINDOWS USED FOR DOORWAY TEST}

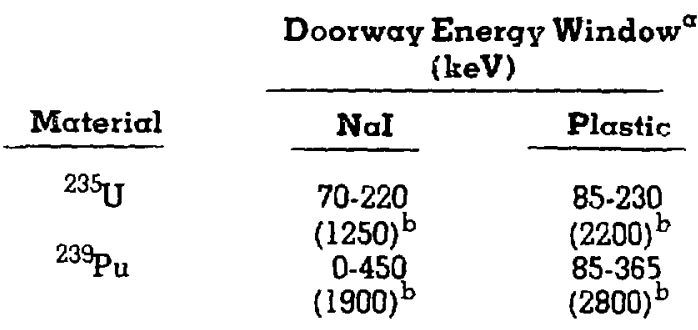

\begin{abstract}
${ }^{a}$ The energy windows shown for plastic are incident photon energy intervals approximate to about $\pm 30 \mathrm{keV}$. The NaI window width uncertainty is about $\pm 5 \mathrm{keV}$.

background count rate $\left(\mathrm{s}^{-1}\right)$, in indicated window. These rates correspond to a natural background of about $25 \mu \mathrm{R} / \mathrm{h}$.
\end{abstract}

Inconsistencies in these tables arise from the limited number of trials used, differences in walking speed between the individucls, differences in the exact source placement, differences in the height and weight of the individuals, which change body shielding, etc. But these data illustrate the "real life" usage of the portal monitor and are not values calculated from static measurements.

Table XIV is intended to point out further the difference in the way the sensitivity varies spatially in the two doorways. This table lists the detection probability for both doorways at a $4 \sigma$ detection level for a number of sources. The minimum sensitivity area of the plastic doorway is its vertical center line, particularly at the top and bottom. This weakness is apparent in the first two columns of the table. For the $\mathrm{NaI}$ doorway the weak points are horizontal planes at waist height, at the top, and, to a smal" ir extent, at the bottom, as is apparent from the results in Table XIV.

For comparison between doorways, the detection efficiency for the four test positions are averaged These results are shown in Table XV. The sensitivities of the two doorways at $4 \sigma$ are so similar that one is not preferred over the other. From the measurements, we would like to determine the mass of material that we can detect $50 \%$ of the time. The overaging between positions prevents us from analytically determining the $50 \%$ source; we can only estimate. These es. timales are shown in Table XVI, where the mass for detection at $50 \%$ confidence is shown for the range of sources tested. The false alarm rate of 3 per $\mathrm{h}$ corresponds to the use of two channels, i.e., $235 \mathrm{~J}$ and ${ }^{238} \mathrm{U}$ simultaneously. For plutonium detection only one channel is used.

Table XVI emphasizes the expected degradation in performance of the doorway monitor for shielded, highly-enriched uranium. Whereas $1 \mathrm{~kg}$ of uranium shielded with $3.2-\mathrm{mm} \mathrm{Pb}$ is probably readily detectable by nonnuclear sensors, 10 or $100 \mathrm{~g}$ can undoubledly be slipped through with very modest shielaing. The situation is, of course, much better for plutonium because of the higher intensity and higher energy gamma activity.

\section{Environmental Testing}

The design for the portal portion of the doorway system anticipated both indoor and outdoor usage without auxiliary heating or cooling. No specific restrictions on outdoor environmental extremes were believed to be inherent in the construction, except that the $\mathrm{NaI}$ scintillators were not to exceed a temperature rate of change of about $5^{\circ} \mathrm{C}$ per hour.

A winter test was carried out with both doorways to delermine the response to the extreme temperature

TABLE XIV

SPATIAL VARIATION OF DETECTOR PROBABILITY FOR SEVERAL SOURCES

Detection Probability In Position Shown for Doorway at $4 a$

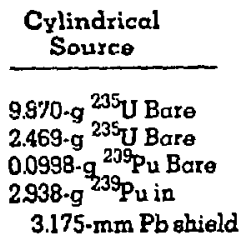

\begin{tabular}{|c|c|c|c|c|c|c|c|}
\hline \multicolumn{4}{|c|}{ Plostic Doorway } & \multicolumn{4}{|c|}{ NaI Doorway } \\
\hline Head & Shoo & $\begin{array}{l}\text { Pants } \\
\text { Pocket }\end{array}$ & $\begin{array}{l}\text { Shirt } \\
\text { Pockot }\end{array}$ & Head & Shoo & $\begin{array}{l}\text { Pante } \\
\text { Pocket }\end{array}$ & $\begin{array}{c}\text { Shirt } \\
\text { Pocket }\end{array}$ \\
\hline $\begin{array}{l}0.90 \\
0.10 \\
0.10 \\
0.95\end{array}$ & $\begin{array}{l}0.50 \\
0.10 \\
0.15 \\
0.55\end{array}$ & $\begin{array}{l}0.95 \\
0.20 \\
0.60 \\
0.95\end{array}$ & $\begin{array}{l}0.95 \\
0.10 \\
0.60 \\
0.95\end{array}$ & $\begin{array}{l}0.30 \\
0.00 \\
0.25 \\
0.80\end{array}$ & $\begin{array}{l}0.80 \\
0.33 \\
0.50 \\
0.80\end{array}$ & $\begin{array}{l}0.95 \\
0.08 \\
0.60 \\
0.95\end{array}$ & $\begin{array}{l}0.95 \\
0.50 \\
0.80 \\
0.75\end{array}$ \\
\hline
\end{tabular}




\section{COMPARISON OF DETECTION PAOBABLITIES FOR THE TWO DOORWAYS}

\begin{tabular}{|c|}
\hline $\begin{array}{l}\text { Source } \\
(q)\end{array}$ \\
\hline $\begin{array}{c}235 \text { u cylinde } \\
2.469 \\
4.6^{\circ} \\
9.870\end{array}$ \\
\hline $2: 5$ I foil \\
\hline $\begin{array}{l}1(0.025 \\
1.9(0.51 \cdot n\end{array}$ \\
\hline $\begin{array}{c}{ }^{235} \mathrm{U} \text { shavin } \\
0.5\end{array}$ \\
\hline
\end{tabular}

1

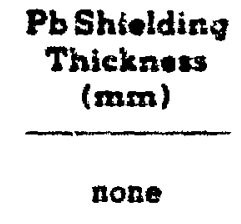

none

$\frac{\text { Doorway Detection Probobilitios }}{\text { Plastic }(4 a) \quad \text { Nal }(4 a) \quad \text { Nal }(50)}$

$\begin{array}{lll}0.10 & 0.20 & 0.10 \\ 0.70 & 0.70 & 0.35 \\ 0.85 & 0.90 & 0.75\end{array}$

$\begin{array}{lll}0.95 & 0.75 & 0.85 \\ 0.80 & 0.80 & 0.50\end{array}$

$\begin{array}{lll}0.40 & 0.45 & 0.15 \\ 0.70 & 0.90 & 0.80\end{array}$

$\begin{array}{llll}1.6 & 0.65 & 0.80 & 0.20 \\ 3.2 & 0.80 & 0.70 & 040\end{array}$

${ }^{238} \mathbf{U}$

300

1002

1002

${ }^{239} \mathrm{Pu}$

0.1

0.284

0.918

2.94

9.82

none
1.6
6.4

none

none

1.6

3.2

6.4

0.85
0.95
0.95

0.35

0.95

0.70

0.85

0.95
0.90

0.95

0.90

0.40

0.50

0.10

0.50

0.20

0.95

0.60

0.03

0.80

0.45

0.60
0.25

a $\mathbf{A} 0.9794 \cdot \mathrm{g}$ and $2.469 \cdot \mathrm{g}$ cylinder together give a signal equivalent to a $4.6 \cdot \mathrm{g}$ cylinder using $S \propto m^{0.68}$.

fluctuation for this geographical area. A location was chosen where the doorways would receive the afternoon sun and cooling would be rapid at sunset. The results of temperature measurements show that the insulation provided by the styrofoam enclosure reduces the rate of change of temperciture to about $2 / 3$ of the ambient rate, if the change is at a moderate rate. However, on the first day, the observed temperature drop was about $15^{\circ} \mathrm{C} / \mathrm{h}$ at sunset.
The Nal crystals cooled at about $10^{\circ} \mathrm{C} / \mathrm{h}$, theretore the restrictions on cryald cooling were not met for this extreme condition. One NaI scintillator crystal fractured and two others showed reduced fulse height resolution, which may indicate froctuzes. The location of the Nal crystal in the styrofoam insulation, with very little insulation around one corner. probably contributed to the temporature shock. 
TRELE XVI

\section{PORTAL MONTTOR \\ DETECTABLE MASS"}

\begin{tabular}{|c|c|}
\hline $\begin{array}{c}\text { Somple } \\
(g)\end{array}$ & $\begin{array}{l}\text { Shielding } \\
(\operatorname{mm} P \mathrm{~Pb})\end{array}$ \\
\hline \multicolumn{2}{|l|}{$93.5 \div{ }^{224} \mathrm{u}$} \\
\hline 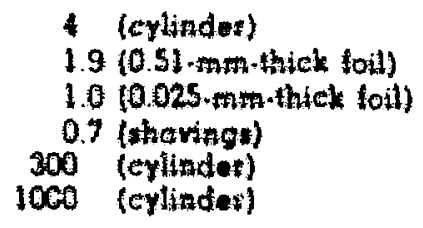 & $\begin{array}{l}\text { Eate } \\
\text { Bare } \\
\text { Dare } \\
\text { Eare } \\
1.6 \\
3.2\end{array}$ \\
\hline \multicolumn{2}{|l|}{$99.6 *{ }^{27}$ U cylinden } \\
\hline $\begin{array}{r}200 \\
500 \\
1000\end{array}$ & $\begin{array}{l}\text { Bate } \\
1.6 \\
6.4\end{array}$ \\
\hline \multicolumn{2}{|l|}{ 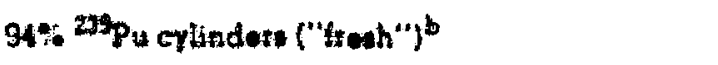 } \\
\hline $\begin{array}{l}0.1 \\
1 \\
3 \\
\cdots \\
\text { so }\end{array}$ & $\begin{array}{l}2610 \\
1.6 \\
3.2 \\
6.4 \\
12.7\end{array}$ \\
\hline \multicolumn{2}{|c|}{ 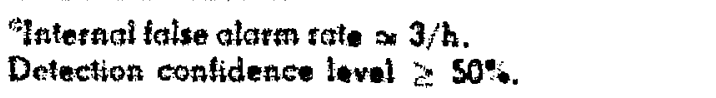 } \\
\hline
\end{tabular}

No luthet chonges were absurved during the lest All steess was apportently pelieved on the first night The effect of the tracturing on opezetion of the Mal doorway wos negligtble. The SCA window had to be widered slightly to accommodat the reduced resalution, but apparently no count zate loss tesulied. Tho observed gain drit was $3 \%$ for the Nal and 6* for the plastis. Such changes ase easily aecom. moduted in the SCA windows itsed.

With the exception of the small drilt, no cdverse effects wete observed for the plastic scintillator pot. tal. The present structural design is odequele for the plastic scintillator lor all recsonoble environments. The results of these fests indicate that the Nal syitem should probably be ured indoors only. although the overall spstom poslozmance was not degraded dus. ing the environmentat test.

\section{Field Tent Experioneo}

Several field lests wete cartied oul at local sites to determine whal probleme would be encountered is installing and uning the doorways, and to ascertass what the folse clarm tate would be in artudi use. The sites eliosen included plutonium and utenium fobriediton afoes where redioative material wes hendled neatby and where the beckground was varible. Adqitional lecation wete chomet where tediocelive sources wate tert of distont and

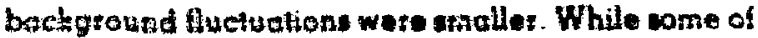
the sites chowen did have atrendanl weunity personnel the operotion of the doorwoy monitor was 45metly unatiended. Inlotmation gained in the test wos derived trom ouxiliary inatrumentation, such as seolots of chent tecotdon tor counting alarms and fintlic, and thom the pholographic record mede by the rystem cometa. On enveral days the operation was monitared viruclly by an individual involved in the development of the syatem. and informetion useful in interpteting the instrumentotion recosds wers obtainad.

1. Inxtallation Requitements. Severd minot probiems, which contrained the placement of tise dootway. were encountered during these tests. A security inspector's tedio transitter with an indoor antenne crused wome interfezence with the operation. of the svstern. Relocating the antenne, in this case, would have provided o wimple solution. Another limiling tacter wes the fivld-ol-view of the comerc The eatrete must be postioned $4.5 \mathrm{~m}$ in lront of the doorway exit to allow o $1.2 \mathrm{~m}$ by $1.8 \cdot \mathrm{m}$ field-ol-view to photogreph both the clock and the individual. The dootwoy therefore must be located where no doors or othes struetures intervene withia $1.5 \mathrm{~m}$ of the exit. If enough room is not avaitable the camerc optics could be chenged oz aot using the camera al cll could also be a logical choice lor the anended station. The widil: of these prototype doorways also limited their positioning. Some corts and hand trucks commonly used at the specitic sites would not fit through the $0.76 \cdot \mathrm{m} \cdot$ wide portal. This problem could be eliminated by specilying peral dimensions for each instollation or by limiting carl sizes. Changing the dimensions of the poztal monitor would obviously aflect its sensitivily.

2. False Alarms. Several circumsiances were encountered that resulted in lalse clarms that were nos. stalistical in naluze. The tirst is ine problem of $a$ sudden rapid increase in background causizg the alarm level to be exceecied. The logic circuit then 
alarms until an updated background is obtained. This requires at least $35 \mathrm{~s}$ for our present logic purameter settings. The update period will be considerably lengthened if traffic is present at the same time, because the traffic would cause occupied alarms that inhibit the background update.

A secona, similar situation wili occur when a dense queue forms in the portal. Bodies in the doorway par. fially shield the detectors and reduce the background count rate. When the queue disperses, a lower background has been stored and the return to normal background causes alarms until the background is agoin updated to the normai level. We observed the queuing effect only at an exchange badge station, where a lengthy wat was required. At stalions where only a badge check is required, the traflic flow is adequate so that the effect does not oc. cur.

The third lype of false c'arm encouniered with the first generation logic occurred during passuge of very large radioactive sources. As noted earlier, the high count rale generated by such passage causes accumulator overflow and continuing alarms until the logic is manually reset. This problem will not occur with the second generation system, which does not use an accumulator.

The last source of tales alarms noted during testing was a vacuum cleaner. On several occasions pictures of the janitor vacuuming the portal were obtained. Increasing the warning level to $5 \sigma$ seemed to eliminate this problem.

All but the third false alarm situation listed are selfremedying; but with the prototypes as presently set, the time for normal operation to resume could be as much as $90 \mathrm{~s}$. During this period the traffic flow would have to be stopped or the doorway located to minimize changing backgrounds and queuing.

3. Film Results. An example of the film record made during an alarm is shown in Fig. 27. Generally, an individual is recognizable and the wall clock is readable when a typical, inexpensive movie editor is used to view the film. However, the magnification is inadequate for reading the dirnital calendar-clock originally used in the doorway, which requires a magnification of 7 for the 1.58-cri-sized numerals. If a numeral height of $2.25 \mathrm{~cm}$ could be obtained, they would be readable on the editor.

The nomal inside hallway lighting was adequate for the black and white MFX or MFA film used. Film readability was also good when daylight was the primary source, although the image quality deteriorates when back-lighting occurs. Reduced lightina at night would make a separate doorway light source necessary for a 24 -h operation. Camera operation was good during the prototype tests; only two film rolls failed to give good results. In one case, an operator error, the cartridge drive was not engaged. In the other, the film failed to properly wind through, although the film indicator moved. Color film gave poor results for indoor operation with existing light. The main fault was lack of the exireme latitude required for typical indoor operation.

Examination of the film record of the field tests provided verification of the alarm and traffic data recorded on scalers. Whenever agreement was not found, the film record was correct, and the total alarm rate could be determined from the film. Whenever traffic was light, the occupied alarm rate could also be estimated from the film record.

The film record was also used to look for individuals who habitually carried radioactive sources that might cause alarms. We anticipated that radium dial watches and medical radioisotopes would be likely sources. The film record was examined and prints were made of the film frames showing individuals who occupied the doorway at the time of an alarm. The record of such individuals is incomplete since identification is difficult or impossible if another person screens the individual from the camera's field-ol-view or is the individual's travel is away from the camera. However, any source capable of alarming $50 \%$ of the time and carried by an individual passing the portal daily would be expected to produce several identifiable photographs auring the 6. to 8-wk test period. Two individuals did appear twice and one individual appeared often. The latter carried residual acticity from a medical diagnostic procedure, whereas the other two are the only evidence for other lower activity sources.

4. Alarm Rate Results. Results derived from field test data are shown in Table XVII. The first two columns display the location and detector type used. In the third and fourth columns the warning level and expected statistical false alarm rate for the given warning level and number of channels used is tabulated. These rates have been discussed previous$\mathrm{l}_{\mathrm{Y}}$ in Sec. VII. B. The traffic rate in the fifth column is tabulated from the number of times the light link was broken. The total observed alarm rate in column six includes both occupied and unoccupied alarms. These alarms arise mainly from the statistical rate (expected value tabulated in column 4), background changes, and the movement of sources nearby. The last of these three contributions dominates the observed rates in the locations where radioactive material was frequently moved nearby (plutonium facility and uranium facility near SNM). For these two areas the total observed alarm rates (column 6 ) 


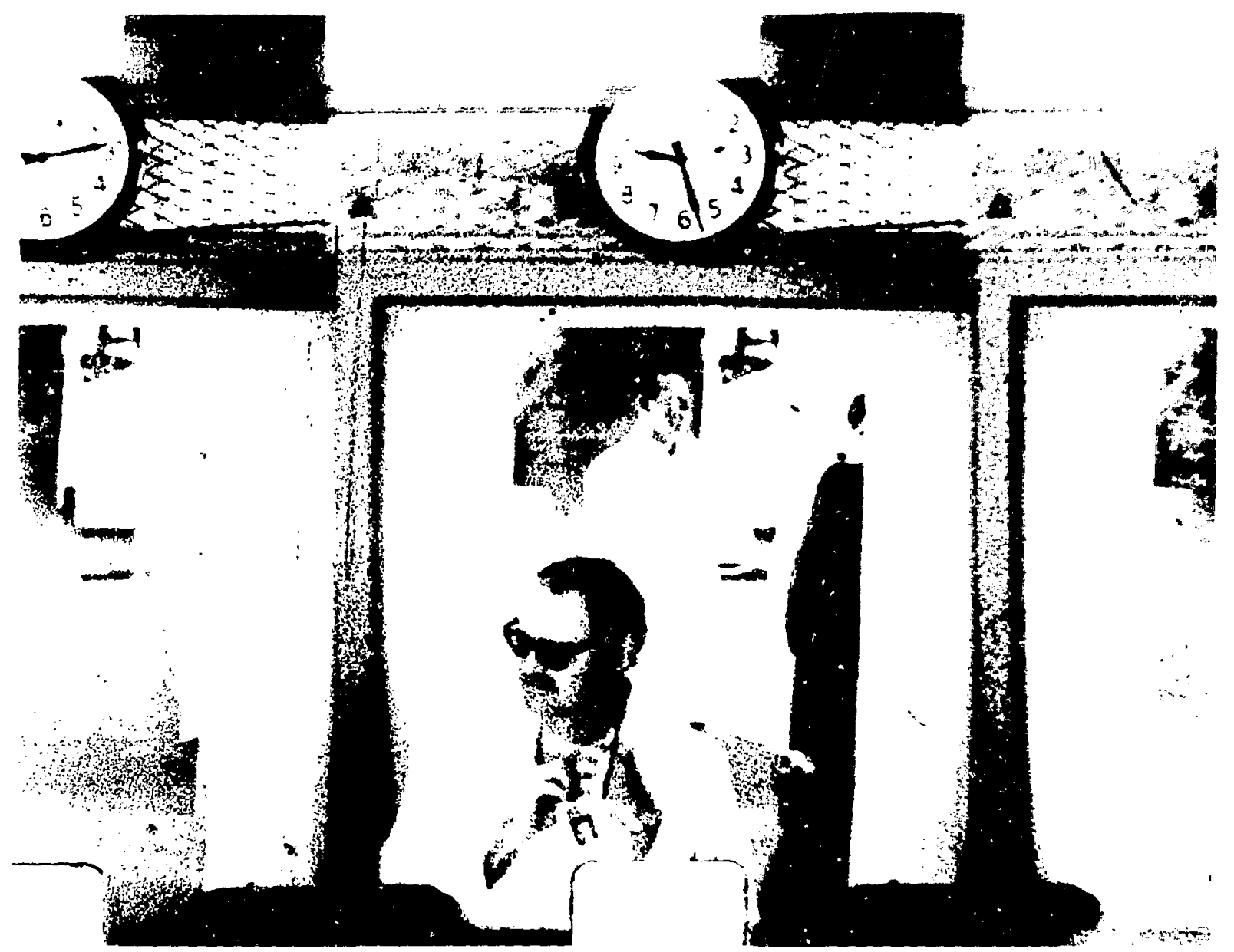

Fig. 27.

An example of the film record made during an alarm.

TABLE :CVII

EIELD TEST RESULTS

\begin{tabular}{|c|c|c|c|c|c|c|c|}
\hline Location & $\begin{array}{c}\text { Doorway } \\
\text { Type }\end{array}$ & $\begin{array}{c}\text { Warning } \\
\text { Lovel }\end{array}$ & $\begin{array}{l}\text { Statistical Alarma } \\
\text { Rate for Number } \\
\text { of Channals and } \\
\text { Warning Lovol Uned } \\
\text { (por h) }\end{array}$ & $\begin{array}{c}\text { Traffic Ratea } \\
\text { Obsoryed } \\
\text { (porh) }\end{array}$ & $\begin{array}{l}\text { Total Alarma } \\
\text { Rate Observed } \\
\text { (por h) }\end{array}$ & $\begin{array}{c}\text { Occupiod Alarma } \\
\text { Rato Obenrved } \\
\text { (por h) }\end{array}$ & $\begin{array}{l}\text { Occupied Alormo } \\
\text { Rato Calculated } \\
\text { from Obsorved } \\
\text { Total Alarm } \\
\text { gate and Traftic }\end{array}$ \\
\hline $\begin{array}{l}\text { Pluionium } \\
\text { facility }\end{array}$ & Plastic & $\Delta \sigma$ & 1.6 & 71 & 23.9 & 0.69 & 0.27 \\
\hline $\begin{array}{c}\text { Uranium } \\
\text { facility } \\
\text { (near SNM) }\end{array}$ & Nol & do & 3.1 & not measuted & 25.1 & 0.31 & not measured \\
\hline $\begin{array}{l}\text { Uranium } \\
\text { facility } \\
\text { (away from SNM) } \\
\text { Administration }\end{array}$ & $\mathrm{NaI}$ & $4 \sigma$ & 3.1 & 23 & 3.46 & 0.10 & 002 \\
\hline $\begin{array}{c}\text { area } \\
\text { Administration }\end{array}$ & Plastic & $4 a$ & 3.1 & 105 & 6.30 & 0.54 & 0.18 \\
\hline area & Plastic & $5 \sigma$ & 0.03 & 105 & 3.34 & 0.35 & 0.10 \\
\hline
\end{tabular}

The indicated rate is calculated for a $24-\mathrm{h}$ period. Traltic wat actually present for a period of about $11 \mathrm{~h}$ per doy. 
are 5 to 10 times those expecled from statintien! krackground fluctuations alone (column 4). Whes the pottal monitor was moved awny from SNM at the uranium lacitily, the total observad alarm rate dropped to essentially that experted from statistical flucfuations.

The observed total alarm rates at the administration atea showed equal contributions from the expected stalistical rete and the ather contributions mentioned above. The $4 a$ and $5 n$ data are consistent The administration area could be expected to have a lower total alarm rate than was observed. However. experimental areas including an acceleralor are nearby: the electrical wiring is poor and powez in terruptions were observed; and the individual with the residual medical isotope had daily business in this area. These probably account for the increased alarm rate observed in this area.

The tolal observed alarm rates (column 6) just discussed should not cause over concern. The security personnel at the portal are alerted with an audio and visual alarm only when an alarm occurs and the doorway is simultaneously occupied. If the doorway is not occupied, then the alarm is a "silent" alarm because the onif action initiated is a photographic record of the unoccupied doorway. Thus the oc. cupied alarm rates (column 7) are the average rales at whicis the guard is alerled with the portal monitor alarm. Whereas this rate will be proportional to the total alarm rate (column 6) and the traftic rate (column 5), the coincidence requirement reduces the important occupied alarm rate by factors ranging from 10 to 50 tor these data. These rates average from less than one to four or five occupied alarms per 8-h period. These rates do not seem excessive exrept that they are average values and one would expect that the most likely time for occurrence would be when traflic flu w is greatest. The film records verity this. They frequently show one or more uccupied alorms during the briel, but high, morning traffic rush

As noted in Table XVII, these values are averages for a 24-h period even though signilicant traftic was preser.t for only about half that time. This has little effect on total observed rates when they arise from statistical fluctuctions only (i.e., uranium facility away from SNM), because these alarms are statistically distributed throughout the entire 24-h period. However, for an urea where most of the alarms are caused by movement of SNM nearby (lor example, plutonium and uranium facilities near SNM) most of the alarms occur during the portir $n$ of the day that traffic is present. The occupied alarm rates during these periods may be approximately 2 to 4 times greater than the listed values in column 7.
The ealculated occupied alarm $x$ ate in column $g$ is obtained from the product of the tolal alarm rale and the fraction of time the doorway is occupied. The latler foctor is obhained from the trallic scole and an assumed l-s occupancy time. The uncertainty discussed above also applies here. Comparing columns $B$ and 7 , the observed rates are always higher than the calculated rate. The diflerence can be altributed to actiol source traflic. Alarms caused by rodium walches, medical radioisotope trectments, and other radicactive sourse tralitic apparently are as big or bigger $c$ problem than slatistical alarms.

In all cases the occupied alorm rates are much higher than those from statistical ellects only and are also very dependent upon the pariseular portal loca. tion. One must not rely excessively on other experience ar calculated rates. On-the-spot experience is necessary to ensure cccurate consideration of all false alarm sources.

\section{PORTAL MONITOR COSTS}

Stricter AEC regulations governing the prolection of SWM and nuclear industry's increasing awareness of the need for additional security measures have increased the interest in this monitoring system. For facilities that hove to install multiple units, cost becomes an increasingly important factor. Expense played an important role in the cresign of this system, and effort was made to keep costs down.

Table XVIII shows estimates of the cost of the porlal monitors described in this report using a second generation logic system. Labor has been included as shown, but no profit is included in these figures. The labor costs on these protolypes are higher than they would be on production versions of the same design. The fabrication cost of the logic module is intermediate between that for a production line (lower) and that for assembly of a first prototype unit (higher). No tigures have been included for the onetime cost of moking printed circuit board masters.

After completion of these two prototypes with the first generation logic, we subrnitted design drawings of the complete system to about 20 commercial ven. dors who might have an interest in manufacturing this instrumentation. Six vendors submitted bids on the system, but funds did not become available to purchase any of our units from a commercial vendor. However, the lowest bids were consistent with our price estimates, considering that a profit has not been included in the Table XVIII values. Systems like these could possibly be purchased commercially for under $\$ 10000$. 


\section{A. Foam Frame Assembly}

1. Mc' erial

2. Fabrication

B. Detector Unito

1. Nal/Pb shielding/PMTo/ voltage dividers

2. Plastic/Pb shiolding/PMTs/ voltage dividers

C. Electronics

1. Preamps ORTEC 113 w/long power cable (2)

2. Clock calendar

3. Light link
a. Material

b. Fabrication

4. High voltage distribution

a. Material

b. Fabrication

5. Low voltage distribution and cabling
a. Material

b. Fabrication

569

II. Instrumentation

A. NIM Bin ORTEC 401A/402A 575

B. High Voltage Supply Power

Designs AEC 315B

C. Amplifier ORTEC 435

D. SCA ORTEC 406A

E. LASL Logic Module (second generation)

1. Material

610

2. Fabrication

660

F. Alarm
1. Material

20

2. Fabrication

III. Surveillance Camera

160

A. Material

15

$\frac{175}{\$ 6649} \quad \frac{175}{\$ 514}$




\section{CONClusions}

It is possible to build a relatively inexpensive portal monitor that can be used at nuclear facilities to help deter the diversion of special nuclear materials by way of monitored exits. These monitors, of course, provide only one component of an effective diversion safequards system. However, the combination of radiation detectors and digital logic explored in this study seem optimum for the purpose.

Clearly this particular type of instrumentation can be defeated by a knowledgeable adversary at a level of diversion that is perhaps 10 to $100 \mathrm{~g}$ of plutonium per pass and 100 to $1000 \mathrm{~g}$ of highly-enriched uranium per pass. From the basic physics of nuclear material, obviously even a drastic increase in expenditure for radiation defectors and a relaxation of the self-imposed constraints on cost and simplicity will not materially alter this situation. We therefore have concluded that radiation surveillance of portals at the level represented by the instrumentation in this report is reasonable and proper but tinat additional assurance should be obtained by other means.

These studies have also demonstrated the necessit for carefully stating acceptable performance standards for equipment of this type. As of December 1973, we concluded that existing AEC guidelines were inadequate in some details. Critical parameters including SNM sample specifications and detection and false alarm probabilities were therefore documented for the AEC.

\section{REFERENCES}

1. Thomas E. Sampson, Paul E. Fehlau, Gary M. Worth, and Carl N. Henry, "Portal Monitor for Diversion Safeguards," Trans. Amer. Nucl. Soc. 17. 302 (1973).

2. Bernard Altshuler and Bernard Pasternack, "Statistical Measures of the Lower Limit of Detection of a Radioactivity Counter," Health Phys. 9, 923 (1963).

3. Nucl. Data, Sect. B. 6, 311 (1971).

4. Nucl. Data, Sect. B. 6, 604 (1971).

5. Nucl. Data, Sect. B. 4, 607 (1970).

6. J. L. Martinez, private communication.

7. K. I. Roulston and S. I. H. Naqvi, Nucleonics. 15 , 86 (1957).

8. J. F. Tinney and J. J. Koch, "Hazzards Control Progress Report," Lawrence Livermore Laboratory report, UCRL-50007-67-3, 6 (1969).

9. D. N. Rao, J. L. Glen, and D. Taylor, "A Square Root Function Generator Using a Binary Rate Divider," Nucl. Instrum. \& Methods. 100, 381-385 (1972).

10. D. Taylor, S. J. Bhatt, and D. N. Rao, "Rate Dividers and Applications in Nuclear Instrumentation," Nucl. Instrum. \& Methods. 93, 585-587 (1971).

11. D. E. Knuth, The Art of Computer Programming. Vol. 2 Seminumerical Algorithms (Addison-Wesley Publishing Co., Reading, Mass, 1969), p.117. 